NASA Technical Memorandum 102440

AIAA-90-0283

\title{
Noise of a Simulated Installed Model Counter- rotation Propeller at Angle-of-Attack and Takeoff/Approach Conditions
}

Richard P. Woodward Lewis Research Center Cleveland, Ohio

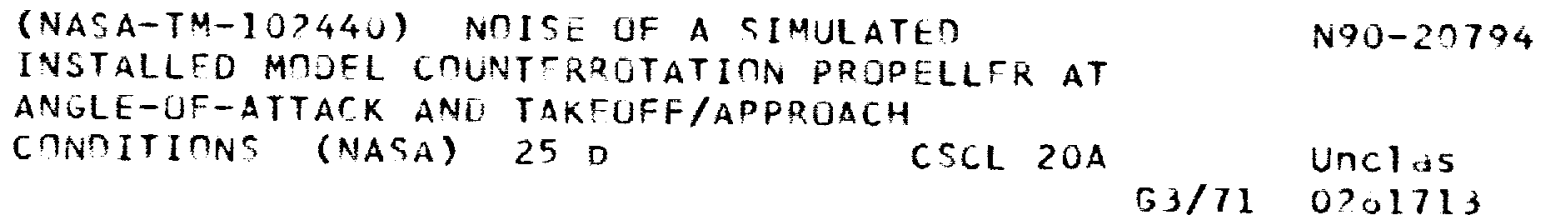

Prepared for the 28th Aerospace Sciences Meeting sponsored by the American Institute of Aeronautics and Astronautics Reno, Nevada, January 8-11, 1990 
$v=-\bar{v}$

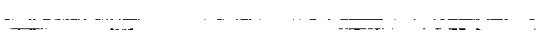

$-\cdots-\cdots+\cdots-$

$-(-\cdots$ 


\title{
NOISE OF A SIMULATED INSTALLED MODEL COUNTERROTATION PROPELLER
}

\author{
AT ANGLE-OF-ATTACK AND TAKEOFF/APPROACH CONDITIONS \\ Richard P. Woodward \\ National Aeronautics and Space Administration \\ Lewis Research Center \\ Cleveland, Ohio 44135
}

\begin{abstract}
SUMMARY
Two modern high-speed advanced counterrotation propeller, F7/A7 and F7/A3 were tested in the NASA Lewis Research Center's 9- by 15-Foot Anechoic Wind Tunnel at simulated takeoff/approach conditions of $0.2 \mathrm{Mach}$. Both rotors were of similar diameter on the F7/A7 propeller, while the aft diameter of the $F 7 / A 3$ propeller was 85 percent of the forward propeller to reduce tip vortex-aft rotor interaction. The two propellers were designed for similar performance. The propellers were tested in both the baseline configuration and "installed" configuration consisting of a simulated upstream nacelle support pylon and fuselage section. Acoustic measurements were made with a "polar" microphone probe which recorded sideline directivities at various azimuthal locations. Aerodynamic measurements were also made to establish propeller operating conditions. The propellers were run at initial blade setting angles for the base"line and installed configurations, and also with the blade setting angles adjusted to achieve equal forward/aft torque ratios at angle of attack with the pylon and fuselage simulation in place. Data are presented for propeller operation at 80 and 90 percent of design speed (the forward rotor design tip speed was $238 \mathrm{~m} / \mathrm{sec}(780 \mathrm{ft} / \mathrm{sec})$. Both propellers were tested at the maximum rotor-rotor spacing of $14.99 \mathrm{~cm}(5.90 \mathrm{in}$.) based on the pitch change axis separation. Data presented in this report are for $0^{\circ}$ and $\neq 8^{\circ}$ propeller axis angle of attack. Results are presented for the baseline, pylon-alone, and pylon and fuselage configurations. The forward and aft rotor power coefficients and fundamental rotor-alone tone levels were directly controlled by propeller axis angle of attack. The second-order rotor-alone tones were strongly influenced by the upstream pylon wake at 80 percent speed; however, rotor-alone mechanisms controlled the tone levels at 90 percent speed. Rotor-rotor interaction tones were essentialiy unaffected by the presence of the simulated installation.
\end{abstract}

\section{INTRODUCTION}

Modern high-performance turboprop aircraft offer the promise of considerable fuel savings while still allowing for a cruise speed approaching that of current turbofan aircraft. Advanced counterrotation propellers may offer from 8 to 10 percent additional fuel savings over similar single rotation propellers at cruise conditions (ref. 1). However, there is considerable concern about the potential noise generated by such aircraft, which includes both in-flight cabin noise and community noise during takeoff and landing.

This paper presents the acoustic results for two model counterrotation propellers which were tested with a simulated installed pusher configuration. The tests were performed in the NASA Lewis 9- by 15-Foot Anechoic Wind Tunnel. Test results are for 0.20 axial Mach number, which is representative of take

Copyright (C) 1990 by the American Institute of Aeronautics and Astronautics, Inc. No copyright is asserted in the United States under Title 17, U.S. Code. The U.S. Government has a royalty-free license to exercise all rights under the copyright ctaimed herein for Governmental purposes. All other rights are reserved by the copyright owner. 
off/approach operation. Sideline acoustic results are presented for both installed and baseline configurations at $0^{\circ}$ and $\pm 8^{\circ}$ propeller axis angle of attack. These data are taken at circumferential locations corresponding to "above" and "below" the installed propeller. Aerodynamic results for the two propellers are also presented to establish the propeller operating conditions and to lend insight to the concurrent acoustic results.

The two test propellers (designated $F 7 / A 3$ and $F 7 / A 7$ ) both had 11 forward and 9 aft blades. Baseline acoustic results for the $F 7 / A 7$ propeller in the 9- by 15-Foot Wind Tunnel are presented in reference 2; corresponding results for the F7/A3 propeller are in reference 3 . Both rotors of the F7/A7 prope 1ler were of essentially the same diameter, while the aft rotor diameter of the F7/A3 propeller was 85 percent of the forward diameter to reduce interaction tone levels resulting from the upstream rotor tip vortex interacting with the downstream rotor (refs. 3 to 5 ). The $F 7$ upstream rotor was common to both propellers. Reference 6 presents acoustic results for these two model propellers with a simulated installation at $0^{\circ}$ propeller axis angle of attack. This paper presents the nonzero angle-of-attack results for these two installed propellers.

\section{APPARATUS AND PROCEDURE}

The NASA Lewis 9- by 15-Foot Anechoic wind Tunnel is located in the lowspeed return leg of the supersonic 8 - by 6-Foot Wind Tunnel. The maximum axial airflow velocity in the tunnel is slightly over 0.2 Mach, which provides a takeoff/approach test environment. The tunnel acoustic treatment was modified to provide anechoic conditions down to a frequency of $250 \mathrm{~Hz}$, which is well below the range of the fundamental tone produced by the model propellers.

Acoustic instrumentation in the 9- by 15-Foot Anechoic Wind Tunnel consisted of two remote-controlled acoustic probes: a "track" probe and a "polar" probe. The probes were instrumented with $0.64 \mathrm{~cm}(0.25 \mathrm{in}$.) condenser microphones. The track probe was fixed to the tunnel floor while the polar probe was attached to the downstream propeller housing, which allowed it to move with the propeller at nonzero angles-of-attack. Only data for the polar probe is presented in this paper.

Figure 1 shows the model propeller and acoustic instrumentation installed in the anechoic wind tunnel. The simulated pusher nacelle support pylon and fuselage section are also in place. The polar probe is seen attached to the propeller housing. As shown in the sketch of figure 2, the polar probe was used to survey a cylindrical field at $61 \mathrm{~cm}(24 \mathrm{in.}$ ) radius from the propeller shaft axis and approximately $\pm 45^{\circ}$ from the downstream rotor plane. The circumferential travel was about $240^{\circ}$, being limited by interference with the propeller support structure.

Figure 3 shows photographs of the two propellers. The A3 rotor had a larger chord to compensate for its reduced diameter; however, its leading edge to pitch change axis was similar to that of the A7 rotor to maintain nearly the same rotor-rotor aerodynamic spacing (affected by blade setting angle) for the same axial rotor-rotor spacing. Both propellers were tested at the "maximum" axial rotor-rotor spacing of $14.99 \mathrm{~cm}(5.90 \mathrm{in.})$. The A3 rotor was tested at a higher blade setting angle $\left(46.4^{\circ}\right)$ compared to that of the A7 rotor 
$\left(39.4^{\circ}\right)$ to achieve the same thrust. Reference 3 also showed that the rotoralone tone level for the $A 3$ rotor was typically $7 \mathrm{~dB}$ lower than that for the A7 rotor even though they were both at the same aerodynamic operating points. This tone level difference was attributed to the lower tangential tip speed of the A3 propeller - a consequence of operation at the same rotational speed with a smaller diameter. Table I presents design characteristics for both propellers at cruise conditions.

The two propellers were operated at blade setting angles which gave simi1 ar aerodynamic performance. These angles were (front rotor/aft rotor) $41.1^{\circ} / 39.4^{\circ}$ for the $F 7 / A 7$ propeller and $41.1^{\circ} / 46.4^{\circ}$ for the $F 7 / A 3$ propeller. These blade setting angles resulted in a nearly equal forward/aft torque split between the two rotors of each propeller in the baseline configuration, and at $0^{\circ}$ angle of attack with the simulated installation in place. The propeller blade angles were adjusted for an equal torque split at $\pm 8^{\circ}$ angle of attack with the installation in place to approximate operating conditions for the General Electric "UDF" full-scale turboprop engine. Table II presents selected aerodynamic parameters for the two propellers at the "takeoff" test conditions. A more complete discussion of the aerodynamic performance of these two installed propellers in the 9- by 15-Foot Wind Tunnel may be found in reference 7 .

Figure 2 also shows how the simulated pylon and fuselage was installed on the test apparatus. Steel beams supported the fuselage and pylon from the base of the model pedestal. The F7/A3 propeller was tested with the pylon-alone, as well as with the pylon and fuselage configuration. The support pylon was fixed at the "nominal" pylon-rotor spacing which was $7.0 \mathrm{~cm}(2.8 \mathrm{in.}$.) axtal spacing between the pylon tralling edge and the forward propeller pitch change axis. The radial distance between the inner flow surface (rotor hub) and the simulated fuselage was $23.2 \mathrm{~cm}(9.1 \mathrm{in}$.$) at the forward rotor plane, and 28.9 \mathrm{~cm}$ (11.4 in.) at the aft rotor plane. This resulted in a radial blade-tip-tofuselage separation of $5.1 \mathrm{~cm}(2.0 \mathrm{in}$.) for the forward rotor (F7, which was common to both propellers). The corresponding blade tip separation for the aft $A 7$ rotor was $11.3 \mathrm{~cm}(4.5 \mathrm{in.})$ and $15.4 \mathrm{~cm}(6.1 \mathrm{in.})$ for the smallerdiameter $A 3$ rotor.

The simulated fuselage had a total length of $224 \mathrm{~cm}(88.2 \mathrm{in.})$. The maximum diameter of $63.5 \mathrm{~cm}(25.0 \mathrm{in}$.$) occurred 47.2 \mathrm{~cm}(18.6 \mathrm{in}$.$) downstream of$ the highlight. The fuselage had a constant $9.24^{\circ}$ taper downstream of this maximum diameter. The fuselage was mounted in the test installation in such a way that its axis of rotation was tilted downward $3.5^{\circ}$ relative to the propeller upstream axis. This resulted in the fuselage surface nearest to the propeller having an effective $5.75^{\circ}$ taper relative to the free-stream tunnel flow (and propeller axis of rotation). Table III presents additional dimensions for the simulated pylon and fuselage.

Both propellers were operated at the "maximum" spacing between forward and aft rotor pitch change axis of $14.99 \mathrm{~cm}(5.90 \mathrm{in.})$. The upstream pylon (when installed) axial distance to the forward rotor was the same for all tests. Acoustic data were taken with a "polar" microphone probe which was mounted on the downstream end of the propeller housing. The polar probe assembly surveyed both the angular and sideline noise fields. The unequal blade numbers of the $11 / 9$ configurations of the two propellers greatly simplified the acoustic analysis of the complicated counterrotation propeller spectra. 
Figure 4 is a sketch of the installed propeller in the anechoic wind tunnel. The forward rotors of both propellers rotated in a clockwise direction viewing downstream; the aft rotors rotated in a counterclockwise direction. The circumferential locations of the sideline directivities are referenced in figure 4 as $\phi=0^{\circ}, 90^{\circ}$, and $180^{\circ}$. The installed propeller was intended to simulate an aircraft pusher configuration. Such an aircraft would have identical engine installations on either side of the fuselage using the same basic propeller. These two engines would have different directions of rotation relative to the airplane fuselage. That is, while the forward rotor of the "engine" sketched in figure 4 might rotate "inboard up," the forward rotor of the engine mounted on the opposite side of the fuselage would then rotate "inboard down." A similar relationship would exist for the aft rotors of the two engines. Thus, sideline data for the first installed engine at $\phi=0^{\circ}$ would correspond to installed data for the second engine at $\phi=180^{\circ}$.

The installed configuration introduces a number of possible noise generation mechanisms in addition to rotor-rotor interaction tones and asymmetrical rotor-alone circumferential noise fields resulting from angle-of-attack operation (refs. 2 and 3). As shown in the cross-section sketch of figure 5 , the upstream pylon wake could easily interact with the propellers to generate pylon-rotor interaction tones at $n_{B P F}$ and $\mathrm{MBPF}_{2}$, where $n$ and $m$ are integers. The simulated fuselage was much too short to generate boundary layer thicknesses comparable to those of an actual fuselage. However, the presence of this simulation could still introduce some boundary layer interaction with the propeller blades, and there could be other flow fields associated with this "fuselage" as well. Reference 3 showed that there was an interaction tone reduction associated with the reduced diameter of the $A 3$ rotor. It is possible that acoustic benefits of reducing the aft rotor diameter could extend to the present study in that the $A 3$ rotor tip is further removed from the fuselageinduced flow disturbances as well as the $F 7$ rotor tip vortex.

\section{RESULTS AND DISCUSSION}

All tests were performed at 0.20 tunnel Mach number. Limited aerodynamic results are presented to establish the propeller operating conditions. Acoustic results are presented as sideline directivities, or maximum sideline level, at $\phi=0^{\circ}$ and $180^{\circ}$ (see fig. 4). Test results are for $0^{\circ}$ and $\pm 8^{\circ}$ propeller axis angle of attack.

\section{Aerodynamic Performance}

Figure 6 is a propeller operating map of the total power coefficient (based on the forward rotor annulus), PQAT, as a function of the corrected forward rotor advance ratio, $\mathrm{J}_{\mathrm{f}} \mathrm{Cos}(\alpha)$. The results in figure 6 are for $0^{\circ}$ propeller axis angle of attack. PQAT is defined as:

$$
\text { PQAT }=\frac{\text { total power }}{\left.(\rho)(\text { rev/sec })^{3}(D)^{3} \text { (annulus area }\right)}
$$

where $\rho$ is the local air density, $D$ is the forward propeller diameter, and $\alpha$ is the propelier axis angle of attack. The results are shown in figure 6 for both the baseline and pylon and fuselage configurations for each propeller. The addition of the simulated pylon and fuselage causes essentially no change 
in the operating line for each propeller - especially at the higher rotational speeds (lower $\mathrm{J}$ ). The maximum difference in the PQAT values for the two propellers at a particular $J$ value is on the order of 0.15 , and is considered insignificant with respect to acoustic performance.

Figure 7 is a PQAT versus corrected $J$ operating map for the F7/A3 propeller at $8^{\circ}$ propeller axis angle of attack. Data are shown for the baseline, pylon-alone, and pylon and fuselage configurations. The addition of the simulated installation has little effect on the overall propeller performance. However, the presence of the pylon, in particular, has a significant effect on the individual rotor power coefficients at this $8^{\circ}$ angle of attack as shown in figure 8. The pylon, which moves with the propeller axis at angle of attack, tends to locally redirect the propeller inflow, with the result that the forward rotor is more highly loaded; the aft rotor more lightly loaded at positive angles of attack. (The reverse is true at negative angles of attack.) This effect is evidenced in the higher power coefficient levels for the forward rotor (fig. $8(a)$ ) and lower levels for the aft rotor (fig. $8(b)$ ). Essentially all of this loading change is due to the pylon portion of the simulated installation. Although the individual rotors are strongly affected by the presence of the installation at angle of attack, the net effect on the propeller is negligible, as was shown in the previous figure.

\section{Acoustic Performance}

Acoustic results will be presented which show the effect of the simulated installation on the propeller tone levels. Maximum sideline sound pressure levels (SPL) for the first and second order $B P F_{f}$ and $B P F_{a}$ tones will be shown for the $\phi=0^{\circ}$ and $180^{\circ}$ azimuthal locations. Results will be presented for the F7/A3 propeller with the pylon-alone at 80 percent design propeller speed, and with the pylon and fuselage installation at 80 and 90 percent speed. Results will also be presented for the F7/A7 propeller with the pylon and fuselage installation at 80 and 90 percent speed to show the acoustic change associated with the larger-diameter $A 7$ aft rotor. The interaction tone levels $\left(B P F_{f}+B P F_{a}\right.$ and $\left.2 B P F_{f}+B P F_{a}\right)$ were essentially unaffected by the presence of the simulated installation. Thus, in the interest of brevity, these results will not be presented in this paper.

Sound pressure level spectra. - The acoustic spectra for counterrotation propellers may be quite complex, consisting of both steady loading and thickness rotor-alone tone harmonics for each rotor, and an array of interaction tones. Figure 9 shows typical spectra for the $F 7 / A 7$ propeller in the baseline and pylon and fuselage configurations at the $\phi=180^{\circ}$ circumferential location. These results are for the $61 \mathrm{~cm}$ (24 in.) sideline polar probe at approximately $65^{\circ}$ from the upstream propeller axis, relative to the aft propeller plane. Rotor-alone tones tend to show a sideline maximum level near the rotor plane $\left(\theta=90^{\circ}\right)$, while interaction tones of ten show highest levels away from this location. The various tone orders are denoted in figure $9(a)$ for the rotor-alone configuration. The first order rotor-alone tones for the forward and aft rotor $\left(B_{f}\right.$ and $B_{a}$ ) are clearly evident. Higher-order rotor-alone tones are not evident in this spectra and are probably buried in the broadband. The first interaction tone $\left(B_{f}+B_{a}\right)$ is quite evident, as are the higher-order interaction tones. The corresponding results for the pylon and fuselage configuration ( $f i g .9(b)$ taken at the same sideline location and propeller operating condition) show that the first order rotor-alone tone levels are increased 
by the presence of the simulated installation. However, the interaction tone levels are essentially unaffected by this installation. Interaction tones for the installed propeller are of two types: Pylon-rotor interactions at $n B P F_{f}$ and $\mathrm{mBPF}_{\mathrm{a}}$, and rotor-rotor interactions at $n B P F_{f}+\mathrm{mBPF}_{\mathrm{a}}$, where $n$ and $m$ take on all possible combinations of positive integer values.

The presence of the upstream pylon tends to locally redirect the propeller inflow at nonzero propeller axis angle of attack with the result of loading the forward rotor and unloading the aft rotor at positive angles of attack (see fig. 8). At negative angles of attack the effect is reversed, with the forward rotor having lower loading and the aft rotor having higher loading. Rotor-alone tone is propagated normal to the advancing rotor blade, and an increase in tone level may be expected when the blade loading is increased, and vise versa. Figure 10 shows "expected" changes in the rotor-alone tone level at the $\phi=0^{\circ}$ and $180^{\circ}$ positions as a function of propeller axis angle of attack. Cyclical blade loading changes associated with operation at $8^{\circ}$ angle of attack will, for example, decrease the tone level at $\phi=0^{\circ}$ and increase the tone level at $\phi=180^{\circ}$ (refs, 2 and 3 ). Pylon-induced loading changes will be additive to angle-of-attack induced tone level changes, with observation of these effects expected at a circumferential location normal to the advancing rotor blade. Thus, pylon effects on the forward rotor should be manifest in tone levels at the $\phi=0^{\circ}$; pylon effects on the aft rotor should yleld acoustic level changes at $\phi=180^{\circ}$.

Most of the following acoustic analysis will be presented in terms of maximum sideline tone level in a format similar to that of figure 10, and the trends indicated in this figure are useful for interpretating the acoustic results. Using this format (rather than presenting raw tone SPL directivity curves) provides a more "global" vlewpoint of the data to facilitate its analysis.

The presence of the simulated fuselage has been shown to significantly affect the first-order rotor-alone tone levels. Aeroacoustic effects include rotor tip interaction with the fuselage boundary layer and possible freestream velocity changes associated with the fuselage blockage. Additionally, the fuselage (and support pylon) could be a source for acoustic reflections. In particular, there seems to be a local flow disturbance associated with the fuselage which manifests itself as a tone level increase normal to the advancing rotor blade as observed previously in the $0^{\circ}$ angle-of-attack results for the installed propellers (ref. 6). A tone level decrease relative to the uninstalled case (reason unknown) was often observed at $180^{\circ}$ to the region of increase.

The first-order rotor-alone tones typically show a broad region of increased level near the $90^{\circ}$ circumferential position. It is possible that this tone increase is related to acoustic reflections from the installation. This phenomenon appears to be limited to the first-order tones, suggesting that reflections from the fuselage and possible "shadowing" of the higher-order tones by the nacelle may be a function of the tone wavelength.

Sideline and circumferential directivities. - Figures 11 and 12 are included to show representative tone SPL directivities for both sideline and circumferential polar probe surveys. Figure 11 shows an example of the continuous sideline directivity data. These results are for the baseline and pylonalone configurations at the $\phi=0^{\circ}$ position and $8^{\circ}$ angle of attack, and are 
for the forward IBPF and 2BPF tones. Pylon flow effects tend to load the forward rotor at this angle of attack. The first-order tone (fig. 11(a)) shows a modest level increase with the pylon in place, with most of the increase seen away from the rotor plane $\left(\theta=90^{\circ}\right)$. However, the 2BPF tone shows a significant increase of about $12 \mathrm{~dB}$ through most of the angular range. The rotoralone tones (IBPF and 2BPF) typically show a maximum level near the propeller plane $\left(90^{\circ}\right)$, and the maximum tone level in this region was used for the tone leve 1 comparisons.

The polar microphone probe could make both sideline and circumferential directivity surveys. Figure 12 shows representative circumferential directivities for the F7/A3 propelier in the baseline, pylon-alone, and pylon and fuselage configurations. These results were measured in the plane of the aft propeller at $0^{\circ}$ angle of attack with the propeller operating at 80 percent design speed. The first-order rotor-alone tone for the forward rotor (fig. 12(a)) shows that there is essentially no circumferential tone level variation for the baseline configuration. However, the addition of the pylon results in a tone level increase near the $\phi=0^{\circ}$ position. One would expect to observe acoustic effects of forward rotor-pylon interaction at this circumferential location according to the expectation that noise is radiated normal to the advancing propeller blade. However, there is also a region of tone noise increase in figure $12(\mathrm{a})$ for $\phi=40^{\circ}$ to $100^{\circ}$ for the pylon-alone configuration. The reason for this tone level increase is not understood, and may relate to acoustic reflections from the installation. The circumferential directivity in the $\phi=150^{\circ}$ to $200^{\circ}$ region shows a periodic character with angle which is suggestive of acoustic reflections. The circumferential directivity for the pylon and fuselage configuration is similar in character to that for the pylon-alone, but with somewhat higher level changes from baseline, suggesting that additional noise is generated by the rotor tip region interacting with the fuselage flow field.

The circumferential directivity results for the aft rotor ( $f i g .12(b)$ ) are essentially a "mirror image" of those for the forward rotor. That is, the aft rotor is rotating in the opposite direction relative to the forward rotor, and the tone level increase associated with pylon-rotor interaction appears near $\phi=180^{\circ}$. The other acoustic effects noted for figure 12(a) follow in similar manner in figure $12(b)$.

The 2BPF forward rotor-alone tone appears to be more strongly affected by the presence of the upstream pylon than is the fundamental (BPF) tone. As seen in figure $12(c)$, the forward rotor $2 B P F$ tone shows a significant increase near the $\phi=0^{\circ}$ position with the pylon in place. The addition of the fuselage results in an additional tone level increase. However, the region of increased tone level near $\phi=90^{\circ}$ observed for the first-order tone is not present for the 2BPF tone. It is possible that this higher-frequency tone is blocked by the propeller nacelle. Finally, the 2BPF tone for the aft rotor (fig. 12(d)) shows essentially no change with the addition of the pylon and/or fuselage, showing that pylon wake effects and/or fuselage-rotor interactions are much less significant for the $A 3$ aft rotor.

Rotor-alone tone directivities tend to peak near the rotor plane. Thus, it is reasonable to quantify tone level changes into a more "global" overview by observing the maximum tone level along the sideline and comparing these values for various propeller configurations. The remainder of the acoustic 
results in this paper will be for the maximum sideline tone levels at the $\phi=0^{\circ}$ and $180^{\circ}$ circumferential positions as a function of propeller axis angle of attack.

F7/A3 propeller with pylon-alone configuration. - The pylon-alone configuration was only tested with the F7/A3 propeller, and blade stress considerations limited the nonzero angle-of-attack data to 80 percent design propeller speed. Aerodynamic interaction of the pylon wake with the propeller was expected to be a major contributor to the installed propeller noise. (Refer to fig. 8 in which the presence of the pylon-alone had a major influence on the individual rotor power coefficients at angle of attack.) References 8 to 10 present results for other model counterrotation propellers which were tested with upstream simulated support pylons and at $0^{\circ}$ propeller axis angle of attack. A relatively lowly-loaded model propeller was tested with an upstream pylon (refs. 8 and 9) which showed tone increases up to $7 \mathrm{~dB}$ with the pylon in place. However, another more highly-loaded advanced propeller (more typical of those of the present study) showed only an average of 1 EPNDB (within data scatter) increase with an upstream pylon in place (ref. 10), suggesting that the acoustic effect of the upstream pylon may decrease with increased propeller loading. The reader should note that the "pylon-alone" was mounted on a support structure and did not benefit from the flow constraints of fuselage surface boundary at the propeller tip region. That is, there exists the possibility of nontypical pylon flow effects near the lower end of the pylon which could affect the resulting pylon-rotor noise generation. The results for the forward and aft rotor power coefficients versus advance ratio (fig. 8) which show essentially no difference for the pylon-alone and pylon and fuselage configurations tend to minimize concerns that the pylon-alone airflow is atypical.

Figure 13 shows the maximum BPF tone level for the F7/A3 forward rotor observed along the $61 \mathrm{~cm}\left(24 \mathrm{in}\right.$.) sideline at the $\phi=0^{\circ}$ and $180^{\circ}$ circumferential positions. This figure clearly shows that loading changes associated with nonzero angle-of-attack operation are the controlling mechanism for changes in this rotor-alone tone level. Small additional tone level changes ( $2 \mathrm{~dB}$ or less) were observed with the addition of the simulated support pylon.

Corresponding results for the maximum aft rotor sideline BPF tone level are shown in figure 14. Somewhat surprisingly, the aft rotor is significantly more sensitive to the presence of the upstream pylon than was the forward rotor, showing up to $5 \mathrm{~dB}$ level changes with the pylon in place. These tone level changes are consistent with the predicted changes outlined in figure 10. For example, local flow changes induced by the pylon at $\alpha=-8^{\circ}$ were expected to somewhat load the aft rotor, with a tone level increase expected at the $180^{\circ}$ azimuthal location.

The 2BPF tone for the forward rotor is quite sensitive to the presence of the upstream support pylon ( $f$ ig. $15(\mathrm{a})$ ), showing up to a $12 \mathrm{~dB}$ increase with the pylon in place at $\alpha=8^{\circ}$ and $0^{\circ}$ azimuthal position. A tone level increase of about $8 \mathrm{~dB}$ was seen at 0 and $-8^{\circ}$ angle-of-attack operation. Smaller 2BPF increases were observed for the forward rotor at the $\phi=180^{\circ}$ position (fig. 15(b)). The controlling mechanism for pylon-rotor interaction for the 2BPF tone appears to be wake interaction rather than pylon-induced local loading effects. Although significant, 2BPF tone level changes with $\alpha$ for the baseline configuration at nonzero angle of attack are not as great as were those for the BPF tone (fig. 13). Note that 2BPF tone levels, even with 
the pylon in place, are generally 10 to $20 \mathrm{~dB}$ lower than first-order tones, and therefore are not very significant in determining overall propeller noise levels.

The 2BPF tone levels for the aft rotor are less sensitive to the presence of the upstream pylon, indicating that pylon-rotor interaction is less significant for the aft rotor (fig. 16). Tone level changes which do occur for the aft rotor may relate more to pylon wake effects than to pylon-induced loading changes. In particular, at $\phi=180^{\circ}$ and $\alpha=8^{\circ}$ ( $\mathrm{fig}$. 16(b)), the aft rotor $2 B P F$ tone shows about a $4 \mathrm{~dB}$ increase with the pylon in place. If the tone level were controlled by pylon loading changes at angle of attack one would expect the aft rotor $2 B P F$ tone to show a decrease with the pylon in place (see fig. $(0(b))$. The corresponding fundamental aft rotor-alone tone (fig. $14(b)$ ) did indeed show a small level decrease at this location.

Installed $F 7 / A 3$ propeller at 80 percent design speed. - While it was not possible to simulate a fuselage of sufficient size to have well-developed boundary layers, etc., the fuselage simulation of the present study did provide results suggestive of a full-scale installation. Flow disturbances from the fuselage would most likely affect the tip region of the propeller. The $A 3$ aft rotor, with its smaller diameter, should be less sensitive to these disturbances than is the larger A7 aft rotor. Reference 6, which presented installed results for this propeller at $0^{\circ}$ angle of attack, showed that a BPF tone increase is often observed normal to the advancing rotor as it passed closest to the simulated fuselage, suggesting local changes in blade loading. A corresponding tone decrease was often observed circumferentially $180^{\circ}$ from this location, and the reason for this observation remains unexplained.

The baseline, pylon-alone, and pylon and fuselage configurations were run with fixed blade setting angles, which, for $F 7 / A 3$, were $41.1^{\circ} / 46.4^{\circ}$ for the forward/aft rotors (see table II). This resulted in changes in the forward/aft rotor torque ratios and power coefficient ratios with propeller axis angle of attack due to localized inflow changes induced by the support pylon. This acoustic study was part of a research program related to the General Electric UDF engine, which uses two free-turbine drives to power the rotors. With this design the full-scale engine blade pitch is controlled such that the rotors always have an essentlally equal torque split. Thus, it was of interest to explore the acoustic effects of adjusting the propeller blade setting angles for equal torque split at $\pm 8^{\circ}$ angle of attack, and these data are also included on the following figures.

Figures 17 to 20 show the acoustic effect of adding the simulated fuselage to the upstream pylon, with these data added to the figures of the previous, pylon-alone section ( $f i g s .13$ to 16). The triangle symbols are for the installed propeller with blade setting angles adjusted for an equal forward/aft torque split.

The maximum sideline BPF levels for the forward rotor (fig. 17) show that the presence of the fuselage tended to increase the tone levels compared to those for the pylon-alone. The $\phi=0^{\circ}$ sideline is normal to the approaching blade when it is closest to the simulated fuselage (fig. 17(a)) with local blade loading-induced noise radiating toward that position. The results of figure $17(a)$ follow the predictions of figure 10, with tone level decreases at $\alpha=-8^{\circ}$, and increases at $\alpha=8^{\circ}$. However, the same rotor is "retreating" 
relative to the $\phi=180^{\circ}$ sideline (fig. $17(\mathrm{~b})$ ). The results at the $180^{\circ}$ sideline tend to support the $0^{\circ}$ angle-of-attack results of reference 6 . That is, a noise reduction was of ten observed at a circumferential location $180^{\circ}$ away from the previously described region of tone level increase. Such is the case for the $\alpha=0^{\circ}$ and $8^{\circ}$ data in figure 17(b). However, at $\alpha=-8^{\circ}$ there is $a$ significant tone level increase at the $180^{\circ}$ sideline with the fuselage in place. The pylon would locally unload the forward rotor at $\alpha=-8^{\circ}$, so this result suggests that a mechanism other than local pylon loading is controlling this tone level.

Operation with the baseline blade setting angles $\left(41.1^{\circ} / 46.4^{\circ}\right)$ at $\alpha=-8^{\circ}$ results in a 0.828 forward/aft torque ratio with the pylon-alone; a 0.810 torque ratio with the pylon and fuselage (Table II). At $\alpha=8^{\circ}$ the torque ratios become 1.201 and 1.280 , respectively. Thus, aerodynamically, the addition of the fuselage increases the rotor loading mismatch over that which was observed for the pylon-alone. The acoustic results of figure 17 also show that changes in blade loading with the pylon and fuselage relate directly to changes in tone level. For example, at $\phi=0^{\circ}$ and $\alpha=8^{\circ}$ (fig. $17(\mathrm{a})$ ), the forward rotor power coefficient is reduced by equalizing the rotor torques, with a corresponding reduction in the BPF tone level.

First-order tone results for the aft rotor with pylon and fuselage (fig. 18) tend to follow the same pattern as was observed for the forward rotor, including tone level changes caused by equalizing the forward/aft torque ratio. At $\phi=0^{\circ}$ and $\alpha=8^{\circ}$ the aft rotor power coefficient is increased by this equal torque ratio, with a corresponding increase in the BPF tone level (which, in this case, brings the installed tone level to essentially the baseline level). Equalizing the rotor torques can further increase the installation-induced tone levels, as seen for the $\phi=180^{\circ}$ and $\alpha=-8^{\circ}$ case in figure $18(b)$.

The addition of the fuselage to the simulated installation had essentially no effect on the 2BPF tone level (with baseline blade setting angles)(figs. 19 and 20). In some instances, equalizing the torque ratio produced a tone level change similar to that observed for the BPF tone (in particular, see fig. 19(b) for $\alpha=8^{\circ}$ ).

Installed F7/A3 propeller at 90 percent design speed. - Tone generation mechanisms are frequently more effective at higher propelier speeds. Figures 21 to 24 present maximum sideline tone level results for the F7/A3 propeller corresponding to the 80 percent results of figures 17 to 20 . Limited data are avallable at 90 percent speed for the installed propeller due to blade stress limitations. In some instances, installed data are only avallable for the equal torque ratio at angle of attack due to this blade stress consideration. As expected, baseline tone levels are considerably higher at this higher propeller speed.

The response of the BPF tone with the installation in place is similar to that observed at 80 percent speed, but with slightly larger variations from the baseline levels (figs. 21 and 22). However, the response of the forward rotor $2 B P F$ tone to the installation ( $f i g .23$ ) is much less than what was observed at 80 percent speed. At 80 percent speed the data strongly supported the concept of pylon wake-forward rotor interaction being a strong noise generation mechanism. However, at 90 percent speed (as evidenced by the equal torque blade setting angle data) this wake is of little significance and is apparently masked 
by the higher overall noise level associated with higher speed operation. The $2 B P F$ tone response of the aft rotor with the simulation in place (fig. 24) was similar to the 80 percent speed results.

Installed F7/A7 propeller at 80 percent design speed. - The F7/A7 propeller featured a common forward rotor with the F7/A3 propelier, and an aft rotor designed for similar aerodynamic performance, but with a larger diameter (see table I). The A3 aft rotor was originally designed to investigate acoustic benefits of reducing aft rotor interaction with the forward rotor tip vortex, and thereby reducing baseline interaction tone levels (refs. 3 to 5). The A3 rotor was shown to have about a $7 \mathrm{~dB}$ lower baseline BPF level due to its lower tip speed when operated at the same rotational speed as was the A7 rotor. An additional potential benefit of the $A 3$ rotor would be reduced interaction with fuselage-induced flow disturbances (see fig. 5). Thus the following presentation for the installed F7/A7 propeller would be expected to show similar forward rotor acoustic performance to that for the F7/A3 propeller (F7 in each case was run with a $41.1^{\circ}$ blade setting angle). However, tone levels for the A7 rotor arising from tip region interaction with installation disturbances would be expected to be somewhat higher than those observed for the A3 rotor. The F7/A7 propeller was only tested in the baseline and pylon and fuselage configurations.

The maximum BPF tone levels for the forward rotor (fig. 25) are essentially identical to those for the $F 7$ rotor in the $F 7 / A 3$ propeller, as was expected. However, BPF results for the aft rotor show that the larger diameter $A 7$ rotor is more affected by the presence of the installation ( $f i g .26$ ) than is the reduced-diameter $A 3$ rotor. In particular, results for the $\phi=180^{\circ}$ sideline, which is the azimuthal location normal to the advancing $A 7$ rotor in the region of the installation, show a slightly greater tone level increase with the installation in place compared to that for the A3 rotor (fig. 18). At $\alpha=-8^{\circ}$, the installed $A 7$ rotor with baseline blade setting angle showed a $132 \mathrm{~dB}$ BPF tone level; compared to the corresponding $123 \mathrm{~dB}$ level for the $\mathrm{A} 3$ rotor. About $7 \mathrm{~dB}$ of this difference is attributable to the lower tip speed of the $A 3$ rotor leaving a net $2 \mathrm{~dB}$ tone level increase for the $A 7$ rotor. (Both rotors had essentially the same design rotational speed.)

The 2BPF response of the forward F7 rotor in the $F 7 / A 7$ propeller and installation in place (fig. 27) is essentially the same as that for the $F 7$ rotor in the F7/A3 propeller. However, the baseline 2BPF tone levels for the F7 rotor in the F7/A7 propeller are somewhat higher than in the F7/A3 propeller - the reason for this tone level difference for the same rotor operating with two propellers may relate to a different potential flow field near the $F 7$ tip region for different diameter aft rotors.

The 2BPF response of the aft $A 7$ rotor with the installation in place (fig. 28) shows somewhat higher levels than for the corresponding A3 rotor (fig. 20). Again, there is evidence that the larger diameter A7 rotor is interacting with the fuselage flow as shown by the higher installed tone levels at $\alpha=0^{\circ}$ and $8^{\circ}$ at the $180^{\circ}$ sideline location, which is normal to the advancing aft rotor in the region of the installation.

Installed F7/A7 propelier at 90 percent design speed. - The fundamental rotor-alone tone response of the $F 7$ forward rotor in the $F 7 / A 7$ propeller (fig. 29) is essentially similar to that for the same propeller in the $F 7 / A 3$ 
propeller. However, the change in BPF tone level for the aft A7 rotor (fig. 30) with the installation in place (relative to baseline levels) is somewhat greater than what was observed for the A3 rotor (fig. 22) again showing that the $A 7$ rotor is interacting with installation flow disturbances, with this interaction taking on greater significance at higher rotational speeds.

Although baseline 2BPF levels for the $F 7$ rotor in both propellers is about the same (fig. 31), this rotor appears to be somewhat more sensitive to the presence of the installation when in the F7/A7 configuration (compare to fig. 23). This suggests that the response of the forward $F 7$ rotor to the installation may be influenced to some degree by the flow field of the aft rotor.

The baseline $2 B P F$ response of the aft rotor ( $f i g .32$ ) shows an increase relative to the corresponding $A 3$ results (fig. 24) which is typical of the increased tone level expected from relative tip speed considerations. Also, the tone level response for the larger-diameter $A 7$ rotor indicates that the rotor tip region is more likely to interact with the fuselage airflow disturbances.

\section{SUMMARY OF RESULTS}

Two advanced counterrotation propellers were acoustically tested in the NASA Lewis 9- by 15-Foot Anechoic Wind Tunnel at simulated takeoff/landing conditions of $0.20 \mathrm{Mach}$. The propellers were tested in the baseline configuration, and with a simulated installed pusher configuration consisting of a support pylon and fuselage. The propellers were tested over a range of rotational speeds and propeller axis angles of attack. Data were taken with the initial blade pitch angles, and with the pitch angles adjusted for equal forward/aft torque splits at the $\pm 8^{\circ}$ angles of attack. Acoustic data were taken with a polar microphone probe which was attached to the downstream propeller housing and could survey sideline directivities at several azimuthal locations. The following significant results were observed in this study:

1. Individual power coefficients for the forward and aft rotors were strongly controlled by the propeller axis angle of attack with the simulated support pylon in place. The addition of the simulated fuselage had a minimal change on the these power coefficients. However, the overall power coefficient was essentially independent of angle of attack.

2. The first-order rotor-alone tones for the pylon-alone configuration with the F7/A3 propeller showed changes up to $4 \mathrm{~dB}$ at $\pm 8^{\circ}$ angle of attack. These changes were directly related to pylon-induced loading changes on the rotors.

3. The forward rotor $2 B P F$ tone level for all test angles-of-attack at 80 percent design propeller speed was up to $12 \mathrm{~dB}$ higher than baseline levels. Smaller increases were noted for the aft 2BPF tone. This suggests that pylon wake-rotor interaction is a significant mechanism for the $2 \mathrm{BPF}$ tone.

4. Introduction of the fuselage to the simulated installation tended to increase the BPF tone level variations from baseline relative to those observed for the pylon-alone configuration, suggesting that local blade loading from fuselage flow disturbances can significantly influence these tone levels. 
5. Fundamental rotor-alone tone levels with the pylon and fuselage in place tend to directly follow blade loading as evidenced by the fact that tone level changes followed changes in the blade pitch angles.

6. The 2BPF tone level, which is thought to be controlled by pylon wakerotor interaction was much less sensitive to the presence of the installation at 90 percent design speed than at 80 percent speed due to masking effects of rotor-alone thickness notse.

7. Use of a smaller-diameter aft rotor may reduce rotor tip interaction with the installation flow field, giving a lower fundamental rotor-alone tone level at some azimuthal locations. This acoustic benefit is combined with baseline rotor-alone tone reductions which are typical of the lower tip speed of the smaller-diameter rotor.

\section{REFERENCES}

1. Mikkelson, D.C., Mitchell, G.A., and Bober, L.J., "Summary of Recent NASA Propeller Research," Aerodynamics and Acoustics of Propellers, AGARD CP-366, AGARD, Neuilly-Sur-Seine, France, 1985, pp. 12-1 to 12-24 (NASA TM-83733).

2. Woodward, R.P., "Noise of a Model High Speed Counterrotion Propeller at Simulated Takeoff/Approach Conditions (F7/A7)," AIAA Paper 87-2657, Oct. 1987 (NASA TM-100206).

3. Woodward, R.P. and Gordon, E.B., "Noise of a Model Counterrotation Prope 1ler With Reduced Aft Rotor Diameter at Simulated Takeoff/Approach Conditions (F7/A3)," AIAA Paper 88-0263, Jan. 1988 (NASA TM-100254).

4. Dittmar, J.H., "Some Design Phillosophy for Reducing the Community Noise of Advanced Counter-Rotation Propellers," NASA TM-87099, 1985.

5. Dittmar, J.H. and Stang, D.B., "Noise Reduction for Model Counterrotation Propeller at Cruise by Reducing the Aft-Propeller Diameter, "NASA TM-88936, 1987.

6. Woodward, R.P. and Hughes, C.E., "Noise of a Model Counterrotation Prope1ler With Simulated Fuselage and Support Pylon at Takeoff/Approach Conditions," AIAA Paper 89-1143, Apr. 1989 (NASA TM-101996).

7. Hughes, C.E. and Gazzaniga, J.A., "Low-Speed Wind Tunnel Performance of High-Speed Counterrotation Propellers at Angle-of-Attack, "AIAA Paper 89-2583, July 1989 (NASA TM-102292).

8. Block, P.J.W., Klatte, R.J., and Druez, P.M., "Counter-Rotating Propeller Noise Directivity and Trends," AIAA Paper 86-1927, July 1986.

9. Block, P.J.W., "Pusher Propeller Noise Directivity and Trends," AIAA Paper 86-1929, July 1986.

10. Magliozzi, B., "Nolse Characteristics of a Model Counter-Rotating PropFans," AIAA Paper 87-2656, Oct. 1987. 
TABLE I. - PROPELLER DESIGN CHARACTERITISTICS

[Cruise conditions.]

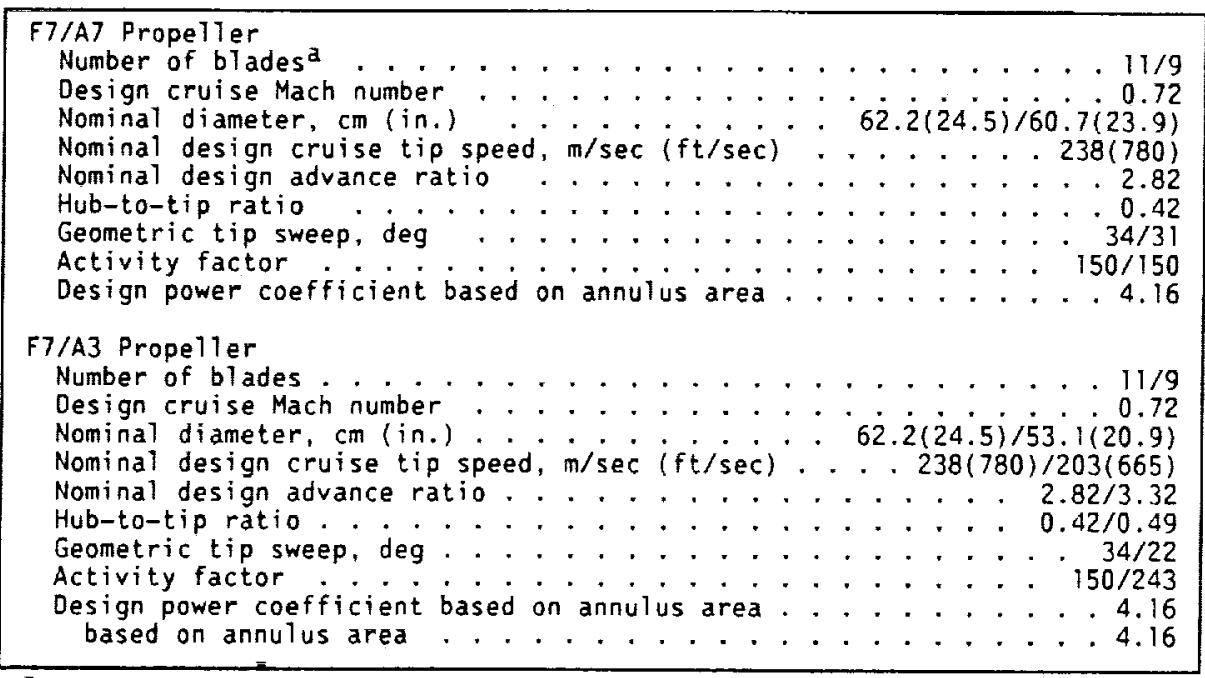

aforward propeller/aft propeller.

TABLE II.- SELECTED AERODYNAMIC PARAMETERS

[Subscripts: $f=$ forward rotor: $A=$ aft rotor.]

\begin{tabular}{|c|c|c|c|c|c|c|c|c|c|}
\hline \multirow{2}{*}{$\begin{array}{c}\text { Propeller } \\
\text { (11/9 blades) }\end{array}$} & \multirow{2}{*}{$\begin{array}{c}\text { Blade } \\
\text { setting angle, } \\
\beta_{f} / \beta_{A} . \\
\operatorname{deg}\end{array}$} & \multirow[t]{2}{*}{ Configuration } & \multirow{2}{*}{$\begin{array}{l}\text { Percent } \\
\text { design } \\
\text { speed }\end{array}$} & \multirow{2}{*}{$\begin{array}{l}\text { Angle of } \\
\text { attack, } \\
\text { deg }\end{array}$} & \multirow[t]{2}{*}{$\mathrm{J}_{\mathrm{f}} \cos \alpha$} & \multicolumn{3}{|c|}{ Power coeffiecients } & \multirow{2}{*}{$\begin{array}{c}\text { Torque ratio, } \\
\tau_{f} / \tau_{A}\end{array}$} \\
\hline & & & & & & $P Q A_{f}$ & $P Q A_{A}$ & PQAT & \\
\hline $\begin{array}{l}\text { | } \\
\mid \\
F 7 / A 3 \\
F 7 / A 3 \\
F 7 / A 3 \\
F 7 / A 7 \\
\text { I/A3 } \\
\text { F7/A7 } \\
\text { F7/A7 } \\
\text { F7/A7 }\end{array}$ & \begin{tabular}{||}
||$_{\downarrow}^{41.1 / 46.4}$ \\
$41.1 / 46.4$ \\
$43.3 / 44.4$ \\
$39.9 / 48.0$ \\
$39.9 / 48.0$ \\
$41.4 / 39.4$ \\
$43.8 / 37.5$ \\
$39.9 / 41.3$ \\
$39.9 / 41.3$
\end{tabular} & $\begin{array}{l}\text { Baseline } \\
\text { Pylon alone } \\
\text { Pylon }+ \text { fuselage } \\
\text { Pylon }+ \text { fuselage } \\
\text { Pylon }+ \text { fuselage } \\
\text { Pylon }+ \text { fuselage } \\
\text { Baseline } \\
\text { Pylon }+ \text { fuselage } \\
\text { Pylon }+ \text { fuselage } \\
\text { Pylon }+ \text { fuselage } \\
\text { Pylon + fuselage } \\
\text { | }\end{array}$ & $\begin{array}{l}80 \\
80 \\
80 \\
90 \\
90 \\
90 \\
80 \\
80 \\
80 \\
90 \\
80 \\
80 \\
80 \\
90 \\
80 \\
80 \\
90 \\
80 \\
80 \\
80 \\
90 \\
90 \\
90 \\
80 \\
80 \\
80 \\
90 \\
80 \\
80 \\
90\end{array}$ & $\begin{array}{r}-8 \\
0 \\
8 \\
-8 \\
0 \\
8 \\
-8 \\
0 \\
8 \\
0 \\
-8 \\
0 \\
8 \\
0 \\
-8 \\
8 \\
8 \\
-8 \\
0 \\
8 \\
-8 \\
0 \\
8 \\
-8 \\
0 \\
8 \\
0 \\
-8 \\
8 \\
8\end{array}$ & $\begin{array}{r}0.965 \\
.969 \\
.964 \\
.860 \\
.861 \\
.852 \\
.963 \\
.968 \\
.954 \\
.865 \\
.967 \\
.968 \\
.962 \\
.862 \\
.959 \\
.963 \\
.859 \\
.967 \\
.972 \\
.968 \\
.864 \\
.871 \\
.868 \\
.961 \\
.974 \\
.965 \\
.868 \\
.966 \\
.964 \\
.859\end{array}$ & $\begin{array}{l}1.726 \\
1.712 \\
1.722 \\
1.804 \\
1.792 \\
1.791 \\
1.534 \\
1.708 \\
1.907 \\
1.793 \\
1.488 \\
1.709 \\
1.917 \\
1.790 \\
1.746 \\
1.701 \\
1.770 \\
1.674 \\
1.659 \\
1.679 \\
1.755 \\
1.739 \\
1.752 \\
1.414 \\
1.629 \\
1.853 \\
1.721 \\
1.733 \\
1.693 \\
1.761\end{array}$ & $\begin{array}{l}1.679 \\
1.654 \\
1.672 \\
1.866 \\
1.856 \\
1.858 \\
1.822 \\
1.671 \\
1.562 \\
1.873 \\
1.812 \\
1.643 \\
1.476 \\
1.833 \\
1.655 \\
1.653 \\
1.850 \\
1.618 \\
1.600 \\
1.590 \\
1.738 \\
1.733 \\
1.712 \\
1.810 \\
1.623 \\
1.464 \\
1.751 \\
1.600 \\
1.692 \\
1.814\end{array}$ & $\begin{array}{l}3.442 \\
3.407 \\
3.443 \\
3.711 \\
3.686 \\
3.687 \\
3.401 \\
3.416 \\
3.508 \\
3.705 \\
3.337 \\
3.391 \\
3.425 \\
3.664 \\
3.435 \\
3.390 \\
3.659 \\
3.334 \\
3.304 \\
3.322 \\
3.536 \\
3.515 \\
3.510 \\
3.266 \\
3.288 \\
3.351 \\
3.514 \\
3.368 \\
3.422 \\
3.617\end{array}$ & $\begin{array}{r}1.013 \\
1.018 \\
1.010 \\
.953 \\
.953 \\
.951 \\
.828 \\
1.008 \\
1.201 \\
.944 \\
.810 \\
1.024 \\
1.280 \\
.962 \\
1.041 \\
1.014 \\
.944 \\
1.017 \\
1.018 \\
1.033 \\
.993 \\
.986 \\
1.005 \\
.769 \\
.989 \\
1.247 \\
.968 \\
1.068 \\
.986 \\
.956\end{array}$ \\
\hline
\end{tabular}


TABLE III. - SIMULATEO INSTALLATION DIMENSIONS

[Dimensions in cm (in.).]

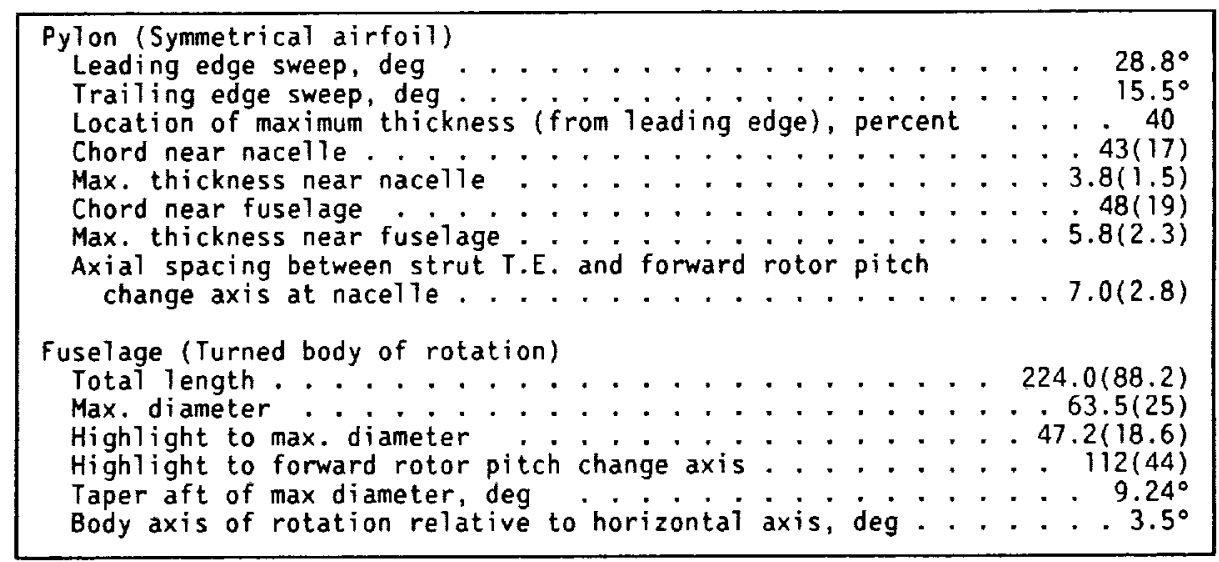

\section{ORIGINAL PAGE \\ BLACK AND WHITE PHOTOGRAPH}

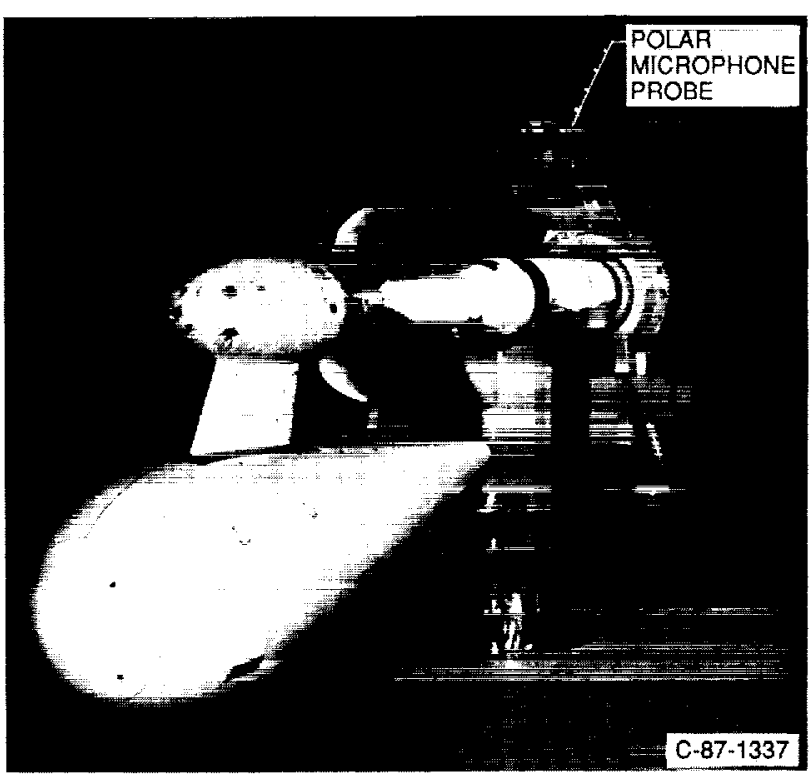

ORIGINAL PAGE IS OF POOR QUALITY

Figure 1. - Counterrotation turboprop model in $9 \times 15$ anechoic wind tunnel, shown with simulated support pylon and fuselage configuration. 


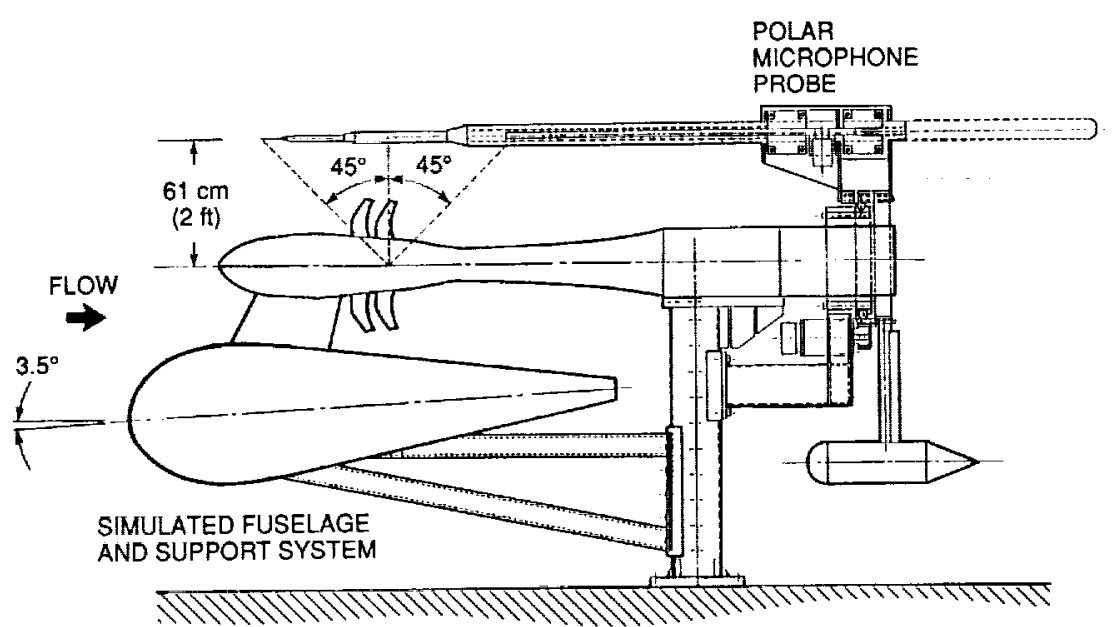

Figure 2. - Sketch of the turboprop model and polar microphone probe.

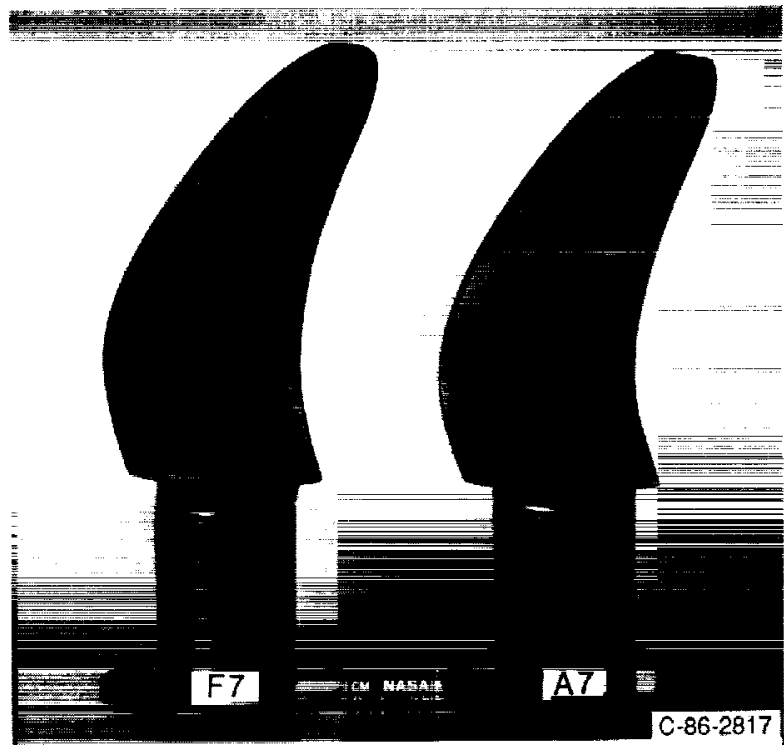

(a) F7/A7.

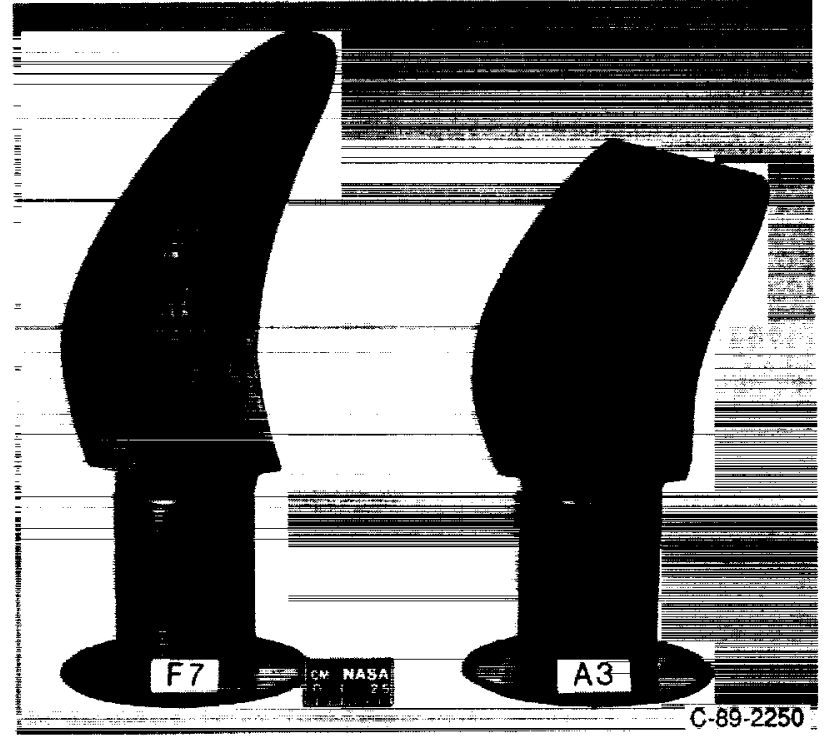

(b) F7/A3, reduced-diameter aft propelter

Figure 3. - Propeller configurations. 


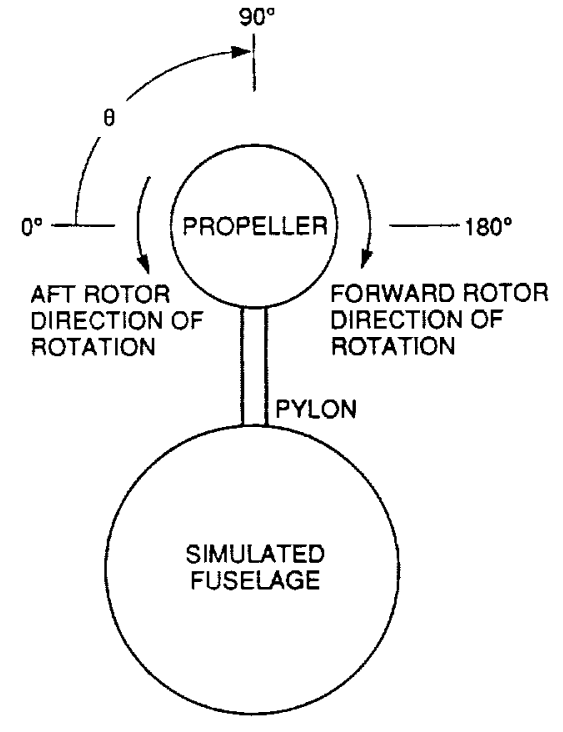

Figure 4. - Sketch of installed propeller viewing downstream showing directions of rotation and circumferential angle convention for noise measurements.

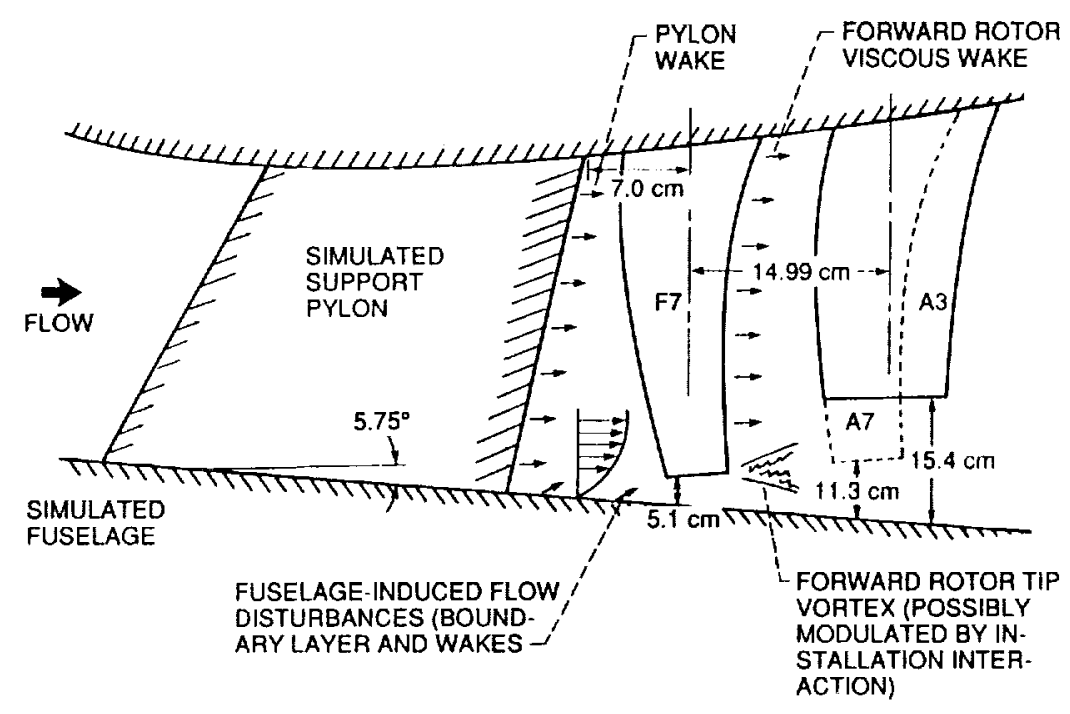

Figure 5. - Possible noise sources for installed propeller.

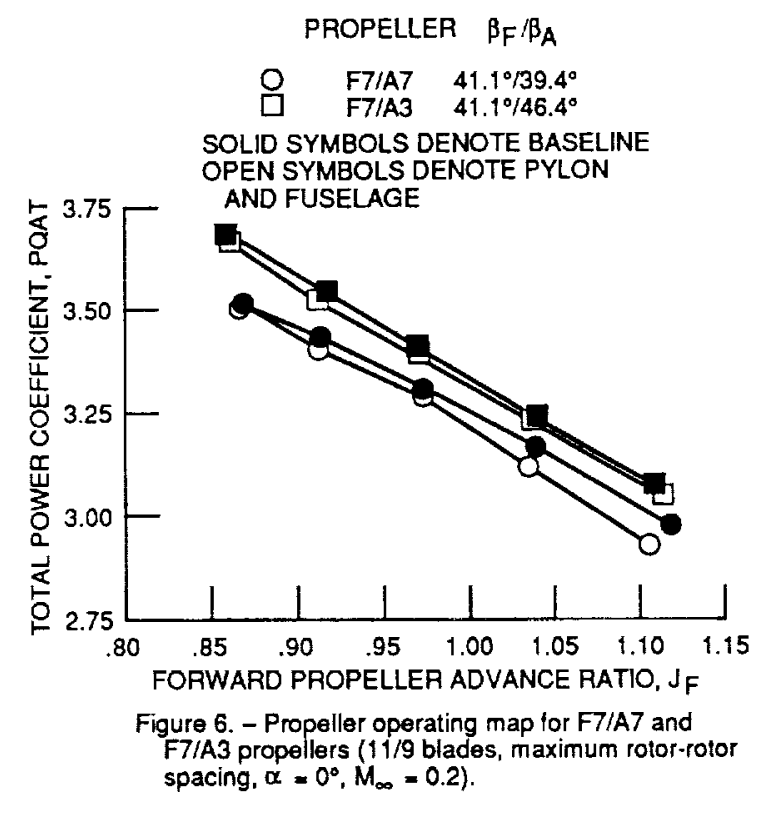

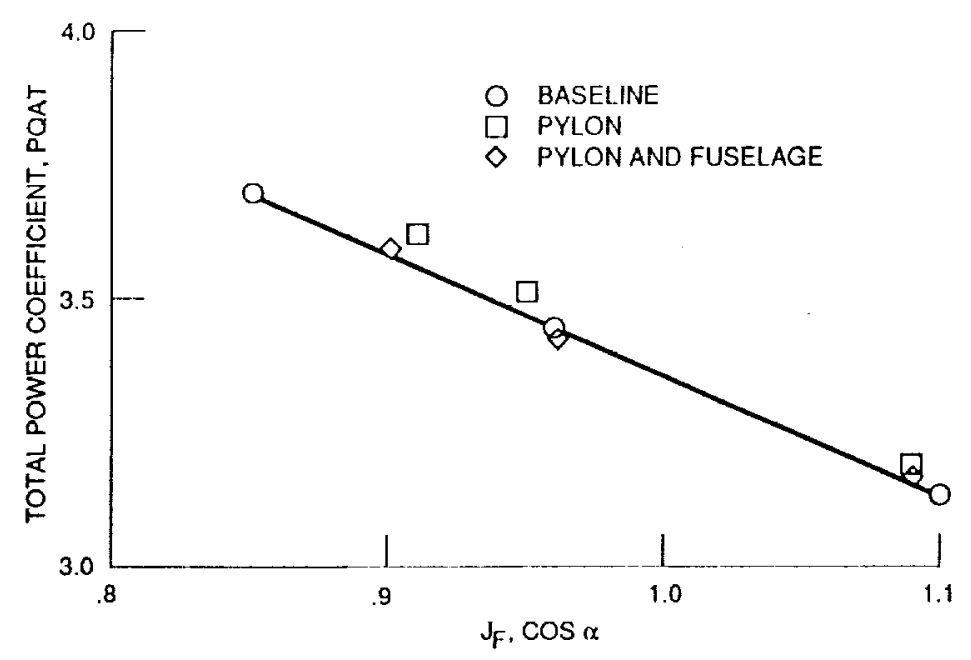

Figure 7. - Propeller operating map for F7/A3 propeller (11/9 blades, maximum rotor-rotor spacing. $\beta_{F} / \beta_{A}=41.1^{\circ} / 46.4^{\circ}, \alpha=+8^{\circ}, M_{\infty}=0.2$ ). 

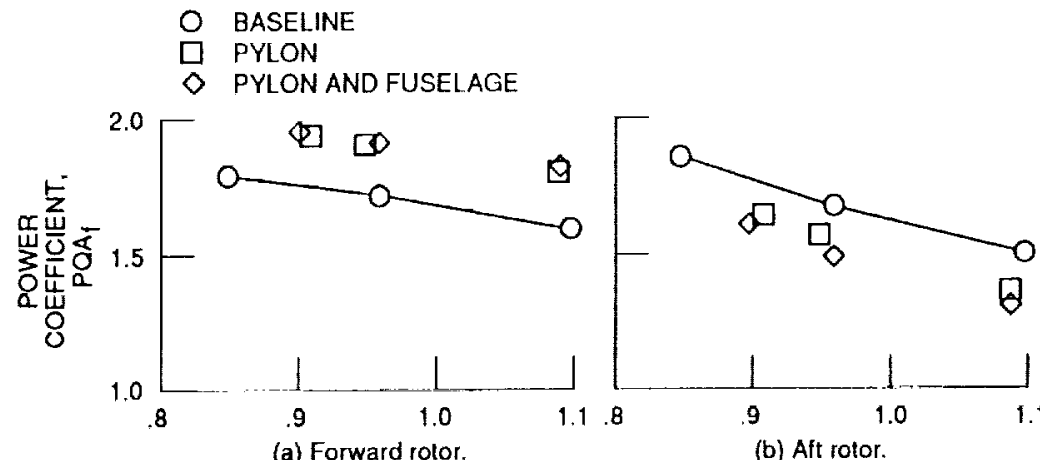

(a) Forward rotor.

$$
\text { J. } \cos \alpha
$$

Figure B. - Propeller operating map for F7/A3 lorward and aft rotors (11/9 blades, maximum rotor-rotor spacing, $\beta_{F} / \beta_{A}=41.1^{\circ} / 46.4^{\circ}, \alpha=8^{\circ}, M_{\infty}=0.2$ ).

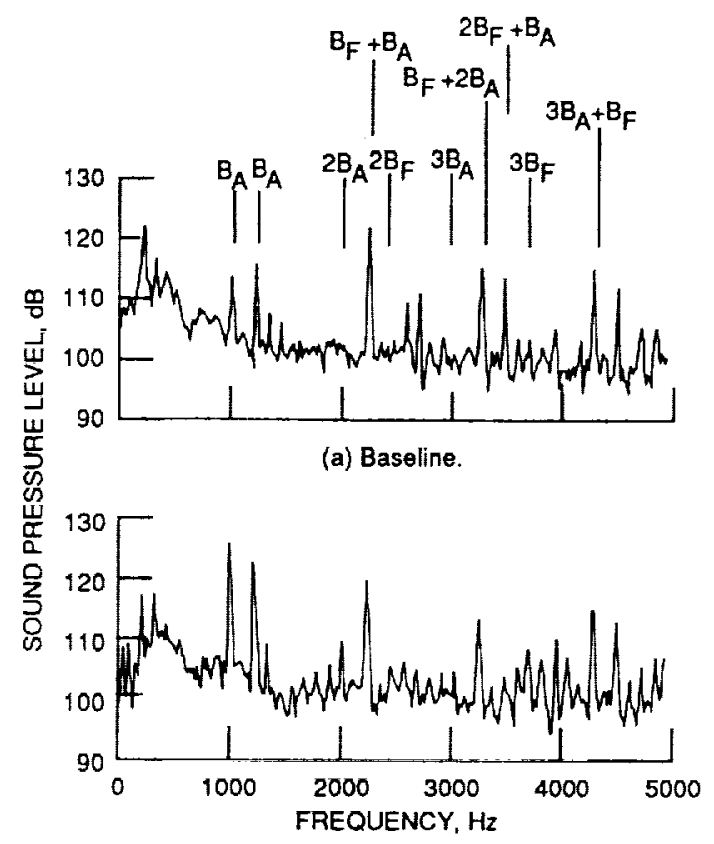

(b) Pylon and fuselage.

Figure 9. - Typical sideline sound pressure level spectra for the F7/A7 model turboprop (11/9 blades, $80 \%$ speed, $\beta_{F} / \beta_{A}=41.1^{\circ} / 39.4^{\circ}, 61 \mathrm{~cm}$ (24 in.) sideline, $\theta=65^{\circ}, \phi=180^{\circ}, M_{\infty}=0.2$ ).

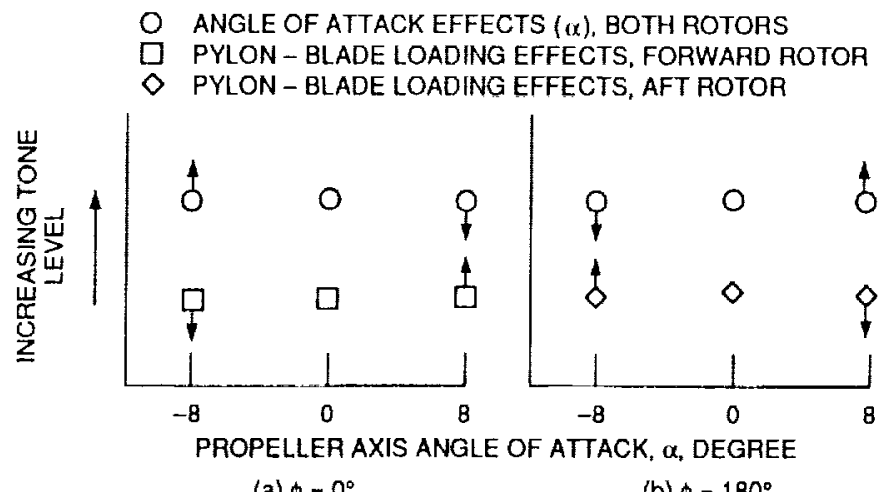

Figure 10. - Expected tone level changes with propelter axis angle of attack. Tone increases produced by pylon-rotor interaction are expected at $\phi=0^{\circ}$ for the forward rotor, and at $\phi=180^{\circ}$ for the att rotor. 


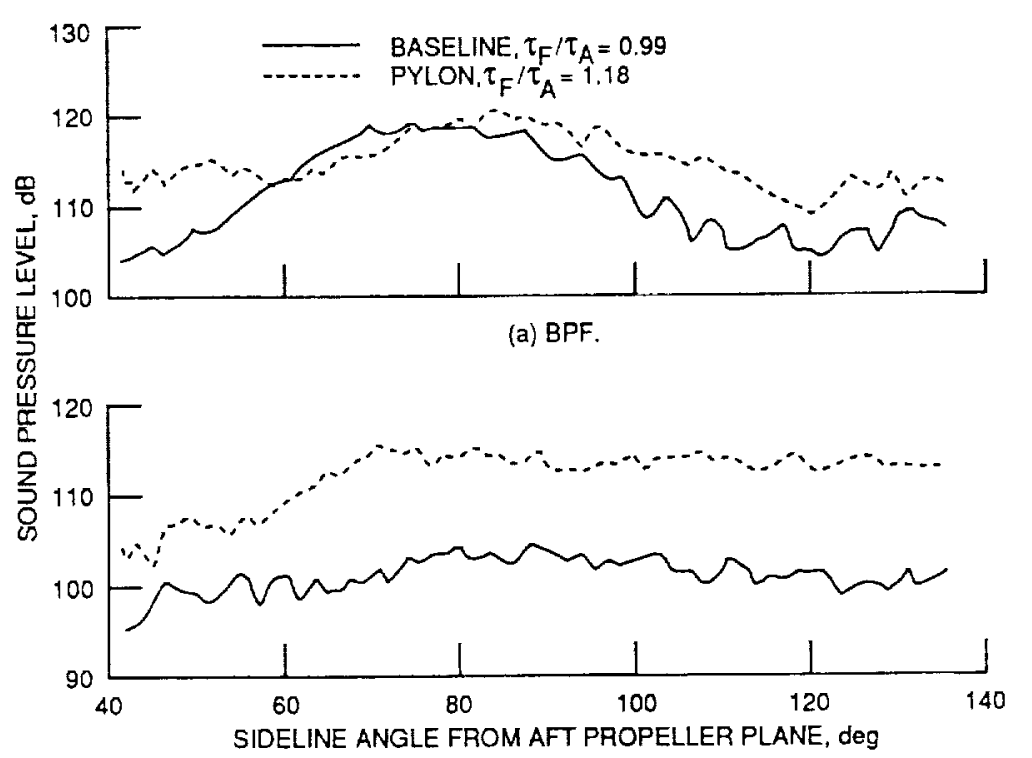

ORIGINAL PAGE IS

OF POOR QUALITY

(b) $2 B P F$.

Figure 11. $-F 7 / A 3$ forward rotor directivity along a $61 \mathrm{~cm}$ (24 in.) sideline.

$\left\langle 0=0^{\circ}, \beta_{F} / \beta_{A}=41.1 \% / 46.4 ; 80\right.$ percent speed, $M_{m}=0.2$.

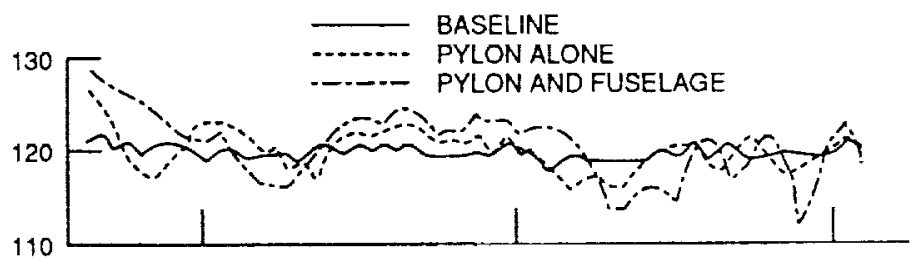

(a) $B P F_{F}$

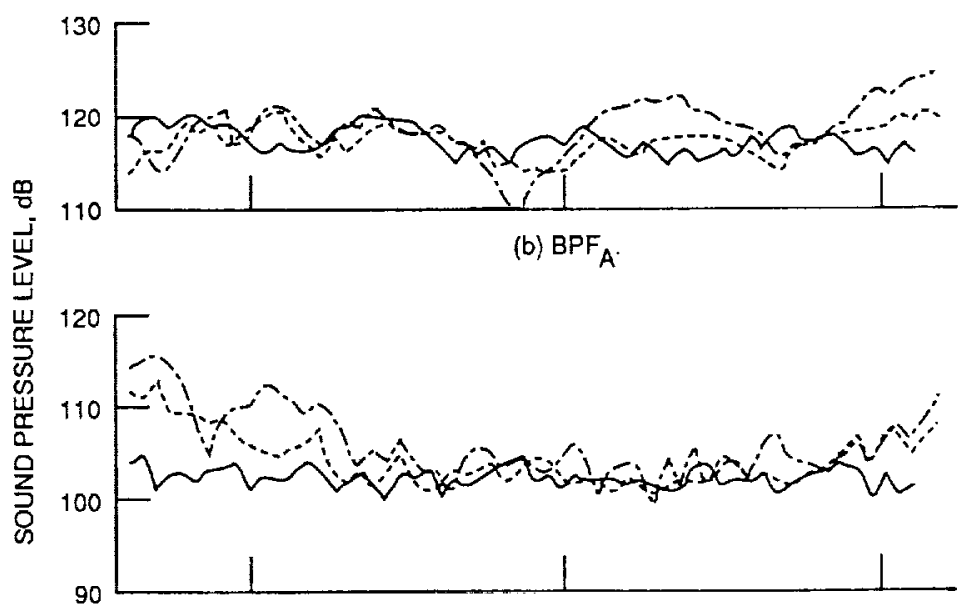

(c) $2 \mathrm{BPF} F$

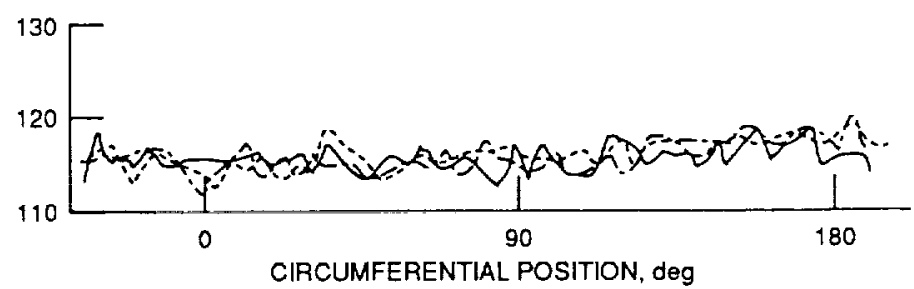

(d) $2 \mathrm{BPF}_{\mathrm{A}}$

Figure 12. - Tone circumferential directivity in aft propeller plane, $F 7 / A 3$ propelier, 80 percent speed. $\left(61 \mathrm{~cm}\left(24 \mathrm{in}\right.\right.$.) radius, $\left.\alpha=0^{\circ}, M_{-}=0.2\right)$. 


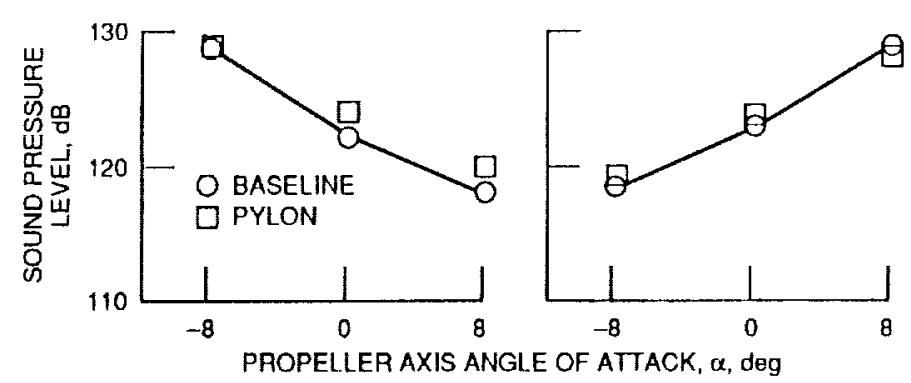

(a) $\phi=0^{\circ}$.

(b) $\phi=180^{\circ}$.

Figure 13. - Maximum F7/A3 BPF $F$ lone level along a $61 \mathrm{~cm}$ (24 in.) sideline as a function of propeller axis angle of attack. $\left(\beta_{F} / \beta_{A}=41.1^{\circ} / 46.4^{\circ}, 80\right.$ percent speed, $\left.M_{\infty}=0.2\right)$. 'Blade selting angles adjusted for equal torque split.

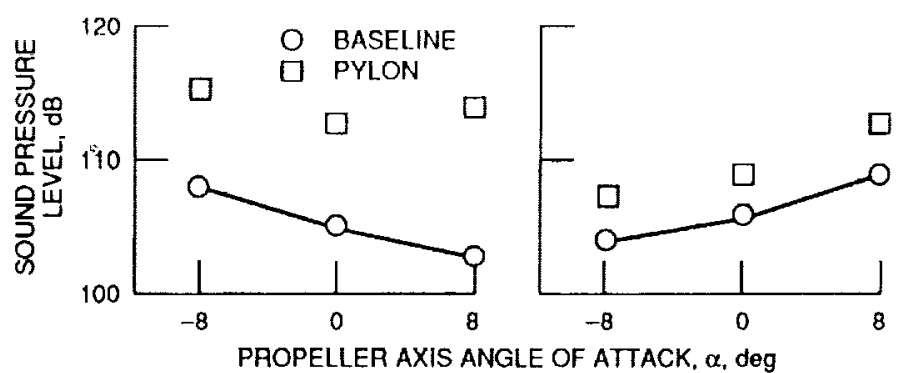

(a) $\phi=0^{\circ}$.

(b) $\phi=180^{\circ}$.

Figure 15. - Maximum F7/A3 2BPF tone level along a $61 \mathrm{~cm}$ (24 in.) sideline as a function of propeller axis angle of attack. $\left(\beta_{F} / \beta_{A}=41.1^{\circ} / 46.4^{\circ}, 80\right.$ percent speed, $\left.M_{\infty}=0.2\right)$.

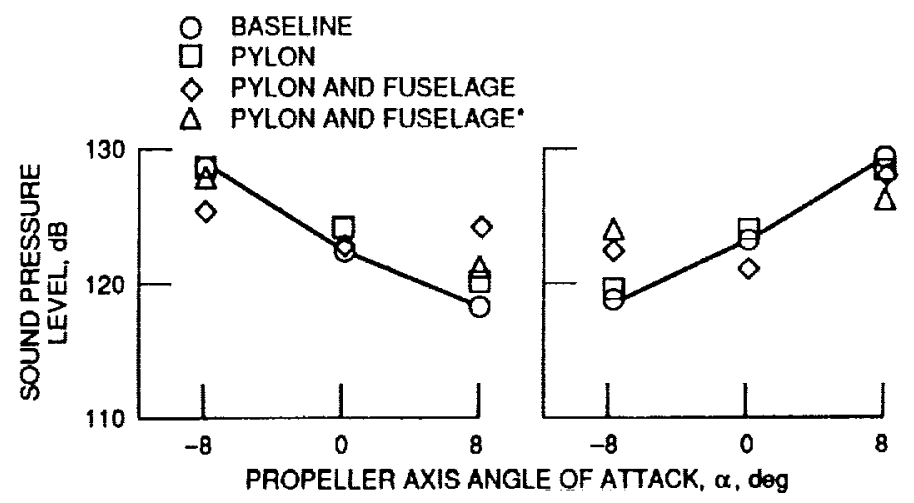

(a) $\phi=0^{\circ}$.

(b) $\phi=180^{\circ}$.

Figure 17. - Maximum F7/A3 BPF $F$ tone level along a $61-\mathrm{cm}$ (24 in.) sideline as a function of propeller axis angle of attack. $\beta_{F} / \beta_{A}=41.1 \% / 46.4^{\circ}, 80$ percent speed, $M_{\infty}=0.2$ ). "Blade setting angles adjusted for equal torque split.

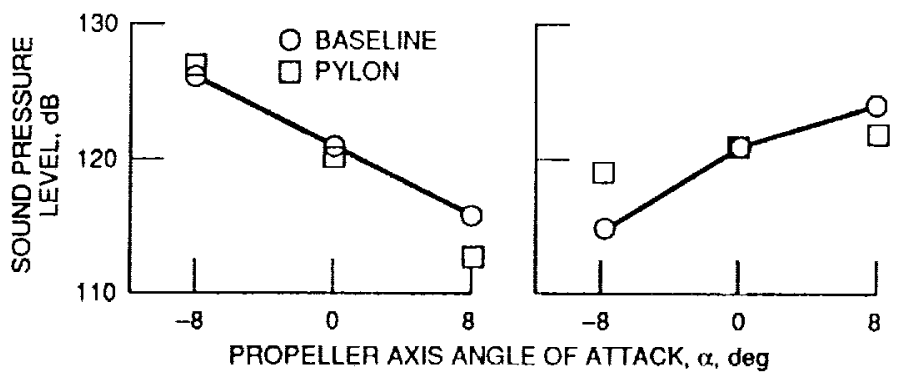

(a) $0=0^{\circ}$.

(b) $\phi=180^{\circ}$

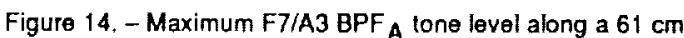
(24 in.) sideline as a function of propeller axis angle of attack. $\left(\beta_{F} / \beta_{A}=41.1^{\circ} / 46.4^{\circ}, 80\right.$ percent speed, $\left.M_{\infty}=0.2\right)$. "Blade selting angles adjusted for equal torque splii.

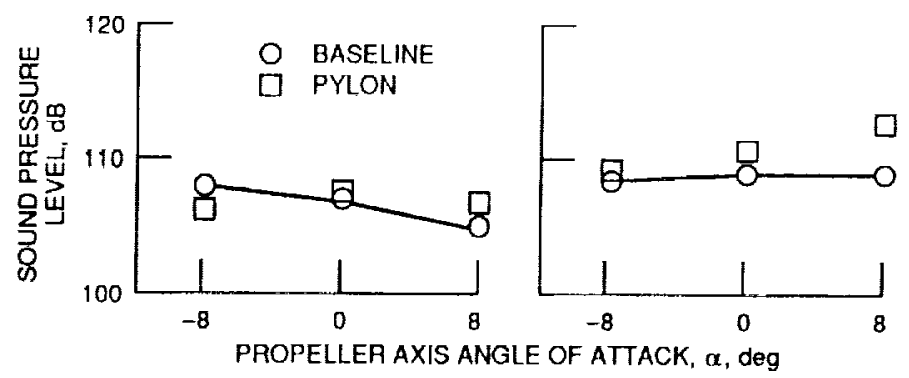

(a) $\phi=0^{\circ}$.

(b) $\phi=180^{\circ}$.

Figure 16. - Maximum F7/A3 2BPF tone level along a $61 \mathrm{~cm}$ (24 in.) sideline as a function of propeller axis angle of altack. $\left\langle\beta_{F} / \beta_{A}=41.1^{\circ} / 46.4^{\circ}, 80\right.$ percent speed, $\left.M_{\infty}=0.2\right)$. "Blade selting angles adjusted for equal torque split.

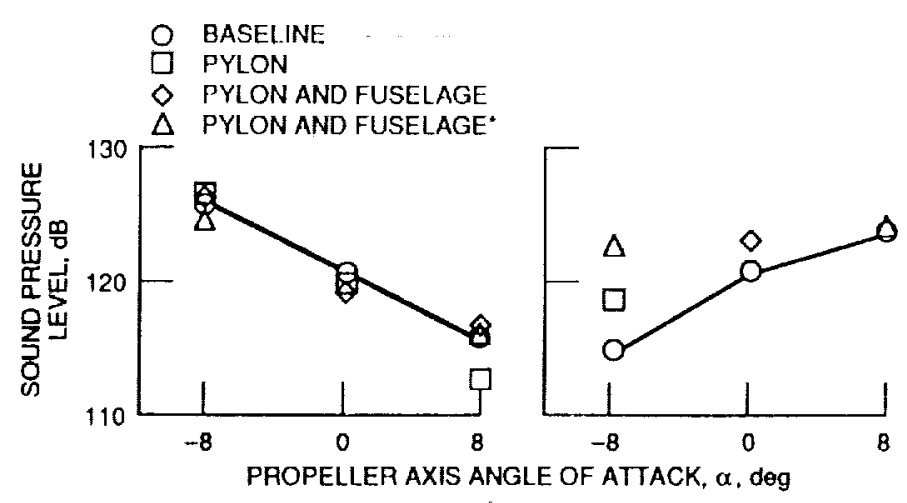

(a) $\phi=0^{\circ}$.

(b) $\phi=180^{\circ}$.

Figure 18. - Maximum F7/A3 BPFA tone level along a $61 \mathrm{~cm}$ (24 in.) sideline as a function of propeller axis angle of attack. $\left(\beta_{F} / \beta_{A}=41.1^{\circ} / 46.4^{\circ}, 80\right.$ percent speed, $\left.M_{\infty}=0.2\right)$. "Blade selting angles adjusted for equal torque split. 


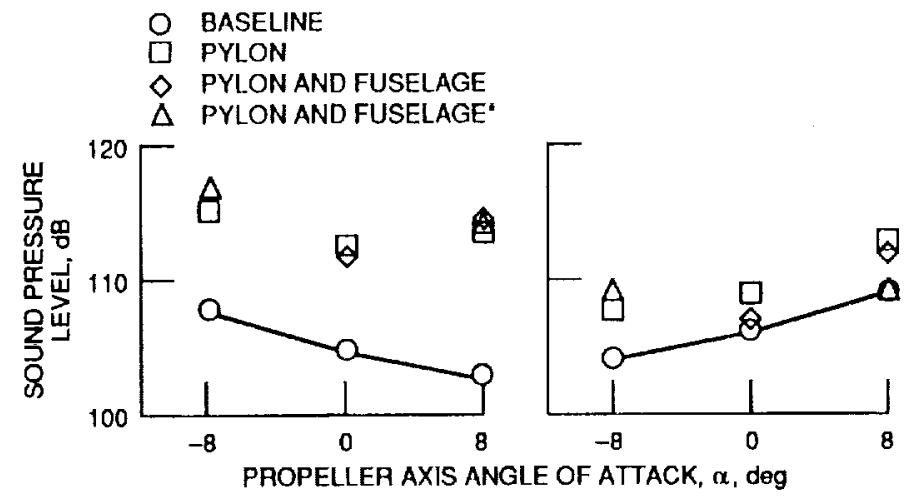

(a) $\phi=0^{\circ}$.

(b) $\phi=180^{\circ}$

Figure 19. - Maximum F7/A3 2BPF tone level along a $61 \mathrm{~cm}$ (24 in.) sideline as a function of propeller axis angle of attack. $\left(\beta_{F} / \beta_{A}=41.1^{\circ} / 46.4^{\circ}, 80\right.$ percent speed, $\left.M_{\infty}=0.2\right)$. "Blade setting angles adjusted for equal torque split.

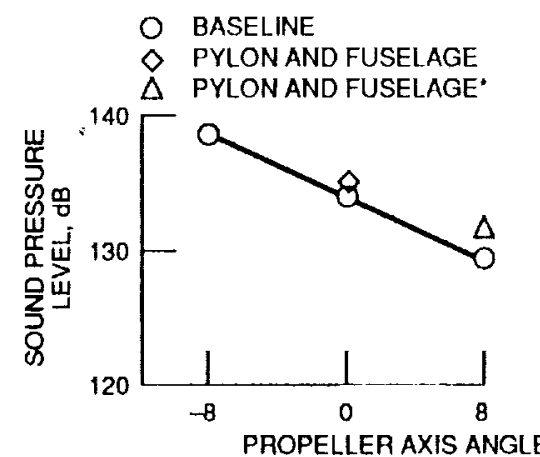

(a) $\phi=0^{\circ}$

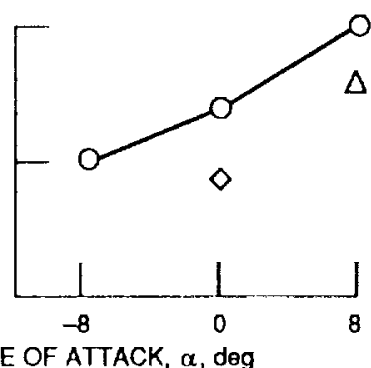

(b) $\phi=180^{\circ}$.
Figure 21. - Maximum F7/A3 BPFF tone level along a $61 \mathrm{~cm}$ (24 in.) sideline as a function of propeller axis angle of allack. $\left(\beta_{F} / \beta_{A}=41.1^{\circ} / 46.4^{\circ}, 90\right.$ percent speed, $\left.M_{\infty}=0.2\right)$. Blade setting angles adjusted for equal torque split.

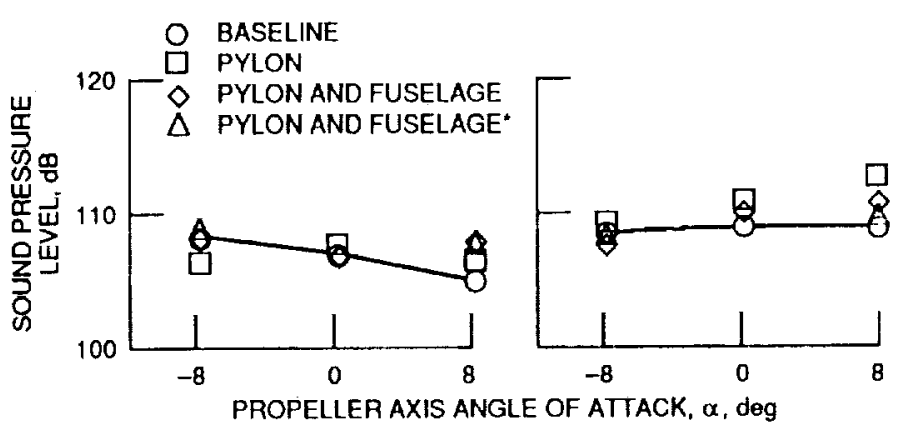

(a) $\phi=0^{\circ}$.

(b) $\phi=180^{\circ}$.

Figure 20. - Maximum F7/A3 2BPF tone level along a $61 \mathrm{~cm}$ (24 in.) sideline as a lunction of propeller axis angle of attack. $\left(\beta_{F} / \beta_{A}=41.1^{\circ} / 46.4^{\circ}, 80\right.$ percent speed, $\left.M_{\infty}=0.2\right)$. Blade setting angles adjusted for equal torque split.

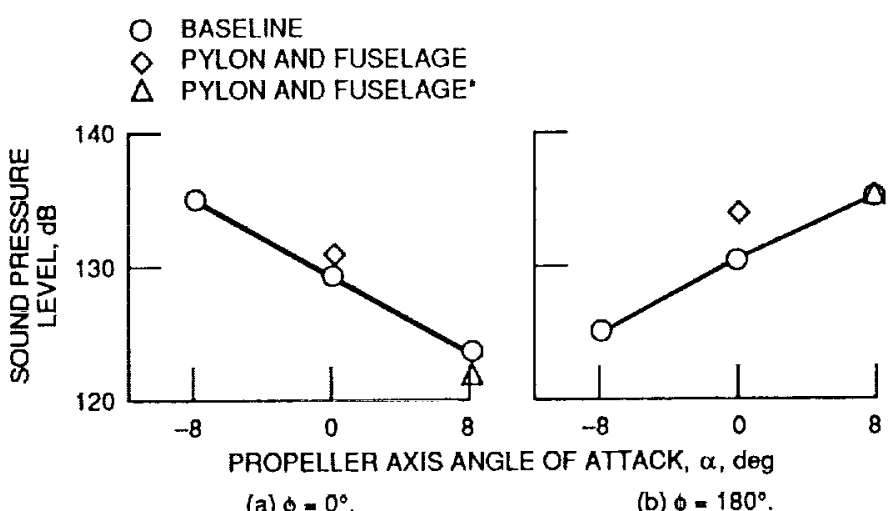

Figure 22. - Maximum F7/A3 BPF tone level along a $61 \mathrm{~cm}$ (24 in.) sideline as a function of propelter axis angle of attack. $\left(\beta_{F} / \beta_{A}=41.1^{\circ} / 46.4^{\circ}, 90\right.$ percent speed, $\left.M_{\infty}=0.2\right)$. " Blade senting angles adjusted for equal torque split.

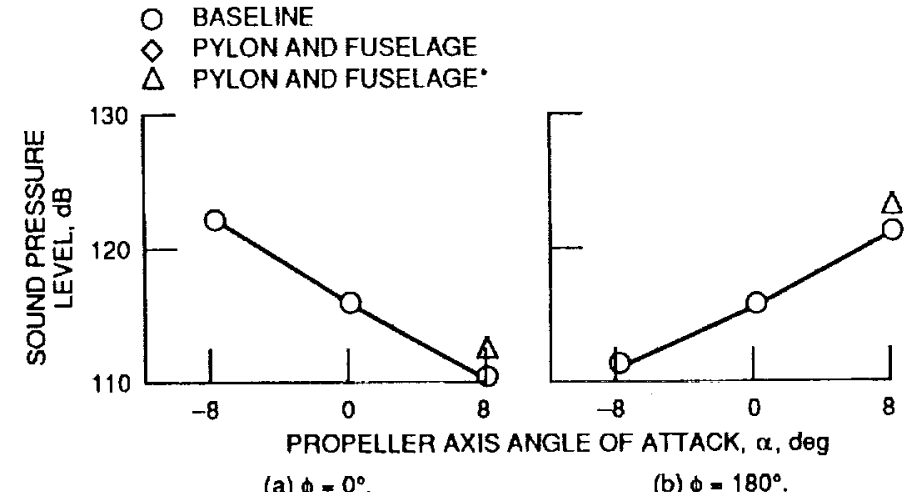

(a) $\phi=0^{\circ}$

Figure 23. - Maximum F7/A3 2BPF tone level along a $61 \mathrm{~cm}$ (24 in.) sideline as a function of propeller axis angle of attack. $\beta_{F} / \beta_{A}=41.1^{\circ} / 46.4^{\circ}, 90$ percent speed, $M_{\infty}=0.2$ ). "Blade setting angles adjusted for equal torque split.

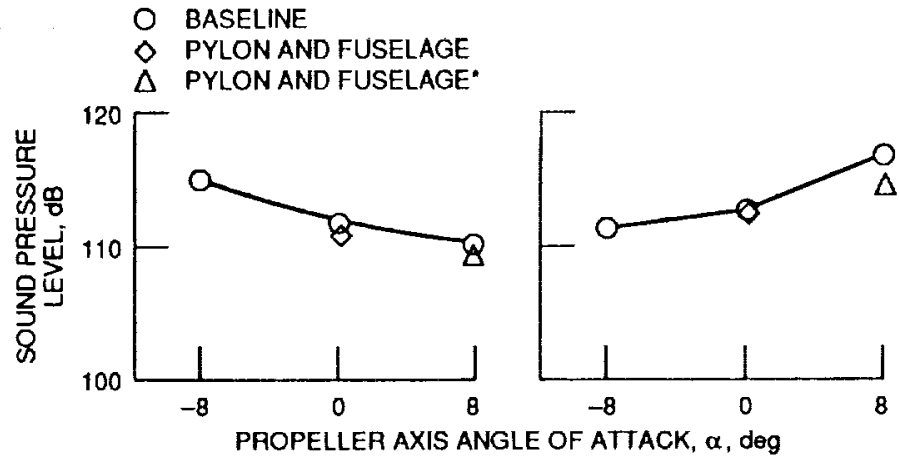

(a) $0=0^{\circ}$.

(b) $\phi=180^{\circ}$.

Figure 24. - Maximum F7/A3 2BPF tone level along a $61 \mathrm{~cm}$ (24 in.) sideline as a function of propeller axis angle of attack. $\left(\beta_{F} / \beta_{A}=41.1^{\circ} / 46.4^{\circ} .90\right.$ percent speed, $\left.M_{\infty}=0.2\right)$. Blade setting angles adjusted for equal torque split. 


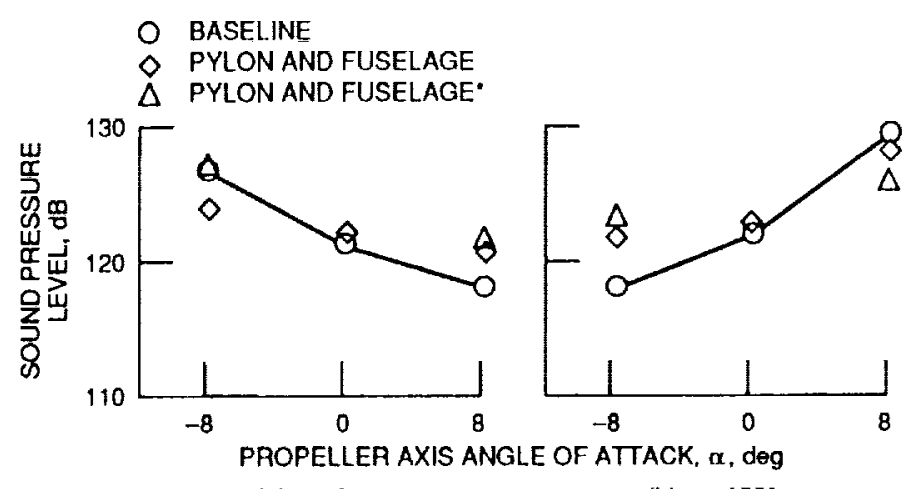

(a) $\phi=0^{\circ}$.

(b) $\phi=180^{\circ}$.

Figure 25. - Maximum F7/A7 BPFF tone level alang a $61 \mathrm{~cm}$ (24 in.) sideline as a function of propeller axis angle of attack. $\left(\beta_{F} / \beta_{A}=41.1^{\circ} / 39.4^{\circ}, 80\right.$ percent speed, $M_{\infty}=0.2$ ). "Blade setting angles adjusted for equal torque split.

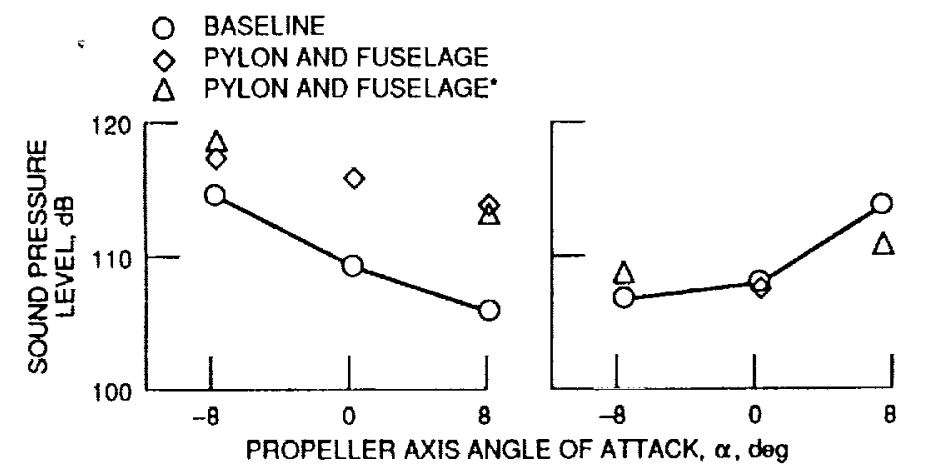

(a) $\phi=0^{\circ}$.

(b) $\phi=180^{\circ}$.

Figure 27. - Maximum F7/A7 2BPF tone level along a $61 \mathrm{~cm}$ (24 in.) sideline as a function of propeller axis angle of attack. $\beta_{F} / \beta_{A}=41.1^{\circ} / 39.4^{\circ}, 80$ percent speed, $M_{\infty}=0.2$ ). "Blade selting angles adjusted for equal torque split.

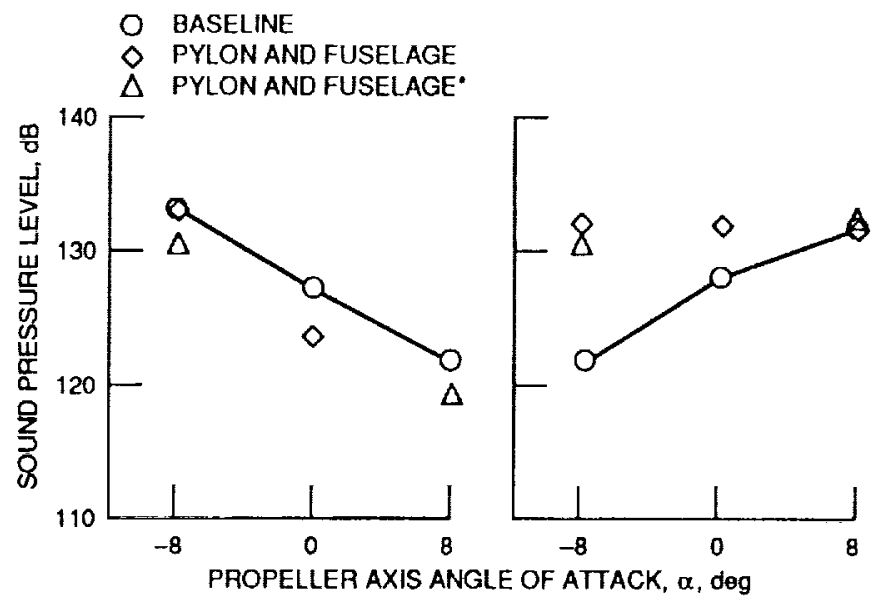

(a) $\phi=0^{\circ}$.

(b) $\phi=180^{\circ}$.

Figure 26. - Maximum F7/A7 BPF tone level along a $61 \mathrm{~cm}$ (24 in.) sideline as a function of propeller axis angle of attack. $\left(\beta_{F} / \beta_{A}=41.1^{\circ} / 39.4^{\circ}, 80\right.$ percent speed, $\left.M_{\infty}=0.2\right)$. Blade setting angles adjusted for equal torque split.

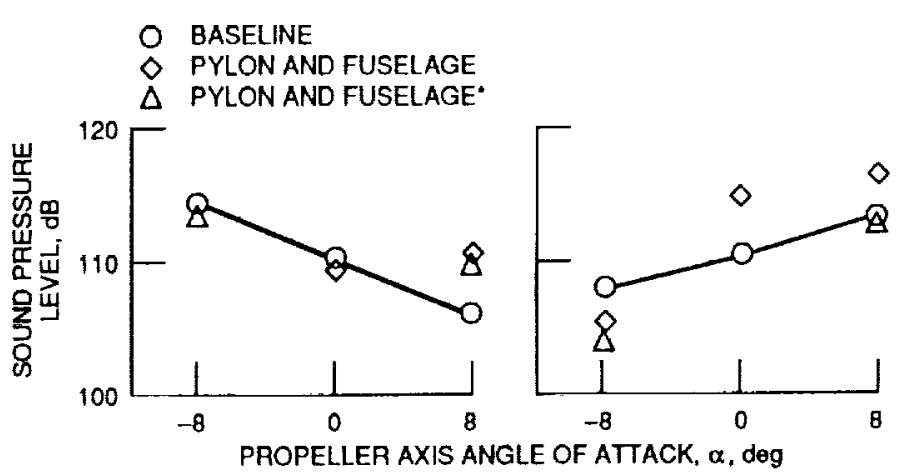

(a) $\phi=0^{\circ}$.

(b) $\phi=180^{\circ}$.

Figure 28. - Maximum F7/A7 2BPF lone level along a $61 \mathrm{~cm}$ (24 in.) sideline as a function of propeller axis angle of attack. $\beta_{F} / \beta_{A}=41.1^{\circ} / 39.4^{\circ}, 90$ percent speed, $M_{\infty}=0.2$ ). ${ }^{\circ}$ Blade setting angles adjusted for equal torque split.

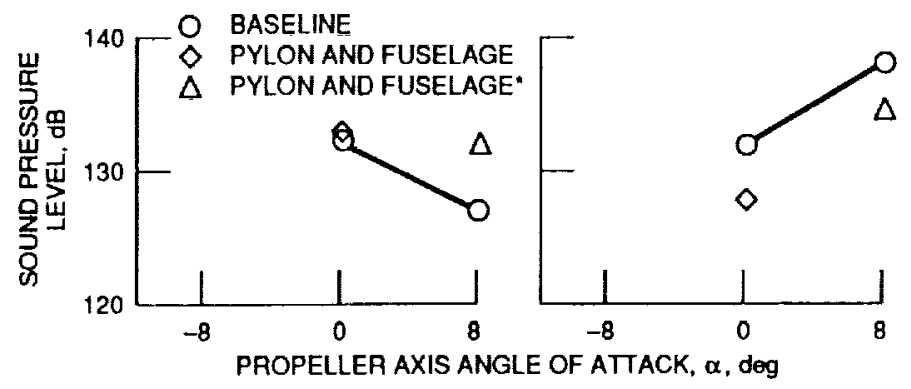
(a) $\phi=0^{\circ}$.
(b) $\phi=180^{\circ}$.

Figure 29. - Maximum F7/A7 BPF $F$ tone level along a $61 \mathrm{~cm}$ (24 in.) sideline as a function of propeller axis angle of atlack. $\beta \beta_{F} / \beta_{A}=41.1^{\circ} / 39.4^{\circ}, 90$ percent speed, $\left.M_{\infty}=0.2\right)$. "Blade setting angles adjusted for equal torque split. 


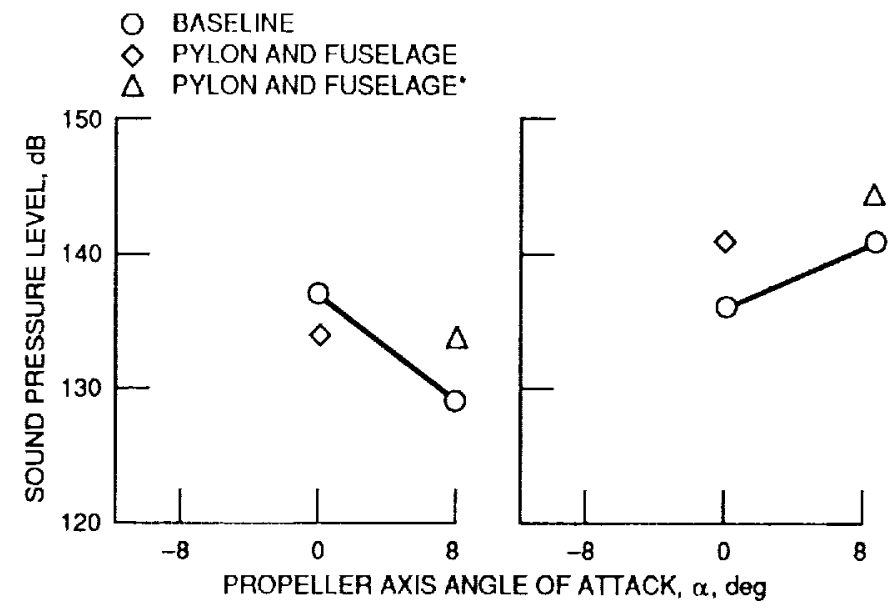

(a) $\phi=0^{\circ}$.

(b) $\phi=180^{\circ}$

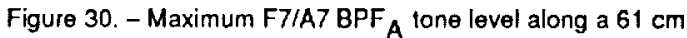
(24 in.) sideline as a function of propeller axis angle of attack. $\beta_{F} / \beta_{A}=41.1^{\circ} \beta 39.4^{\circ}, 90$ percent speed, $M_{\infty}=0.2$ ). 'Blade setting angles adjusted for equal torque split.

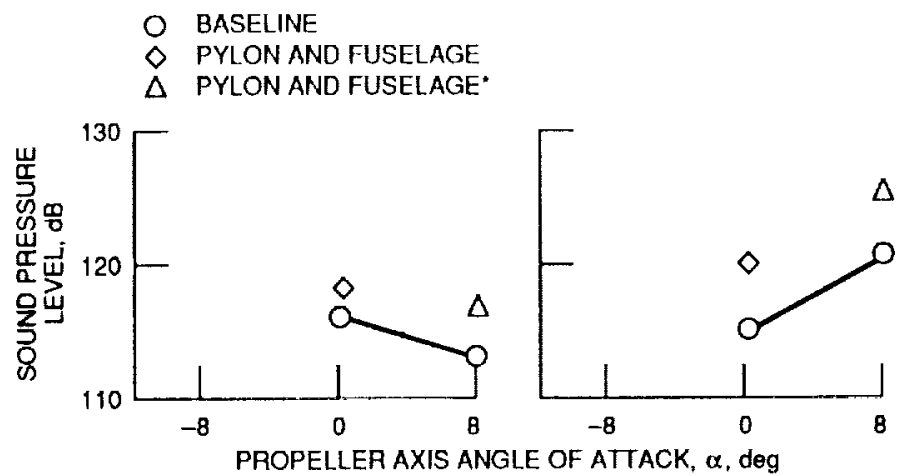

(a) $0=0^{\circ}$.

(b) $\phi=180^{\circ}$.

Figure 31. - Maximum F7/A7 2BPF $F$ tone level along a $61 \mathrm{~cm}$ (24 in.) sideline as a function of propeller axis angle of attack. $\left(\beta_{F} / \beta_{A}=41.1^{\circ} / 39.4^{\circ}, 90\right.$ percent speed, $M_{\infty}=0.2$ ). "Blade setting angles adjusted for equal torque split.

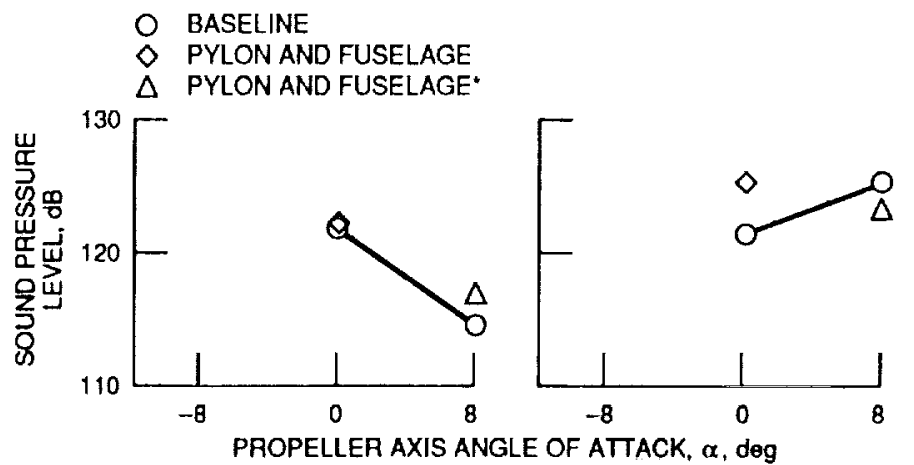

(a) $\phi=0^{\circ}$.

(b) $\phi=180^{\circ}$.

Figure 32. - Maximum F7/A7 2BPF tone level along a $61 \mathrm{~cm}$ (24 in.) sideline as a function of propeller axis angle of attack. $\beta_{F} / \beta_{A}=41.1^{\circ} / 39.4^{\circ}, 90$ percent speed, $M_{\infty}=0.2$ ). Blade setting angles adjusted for equal torque split. 


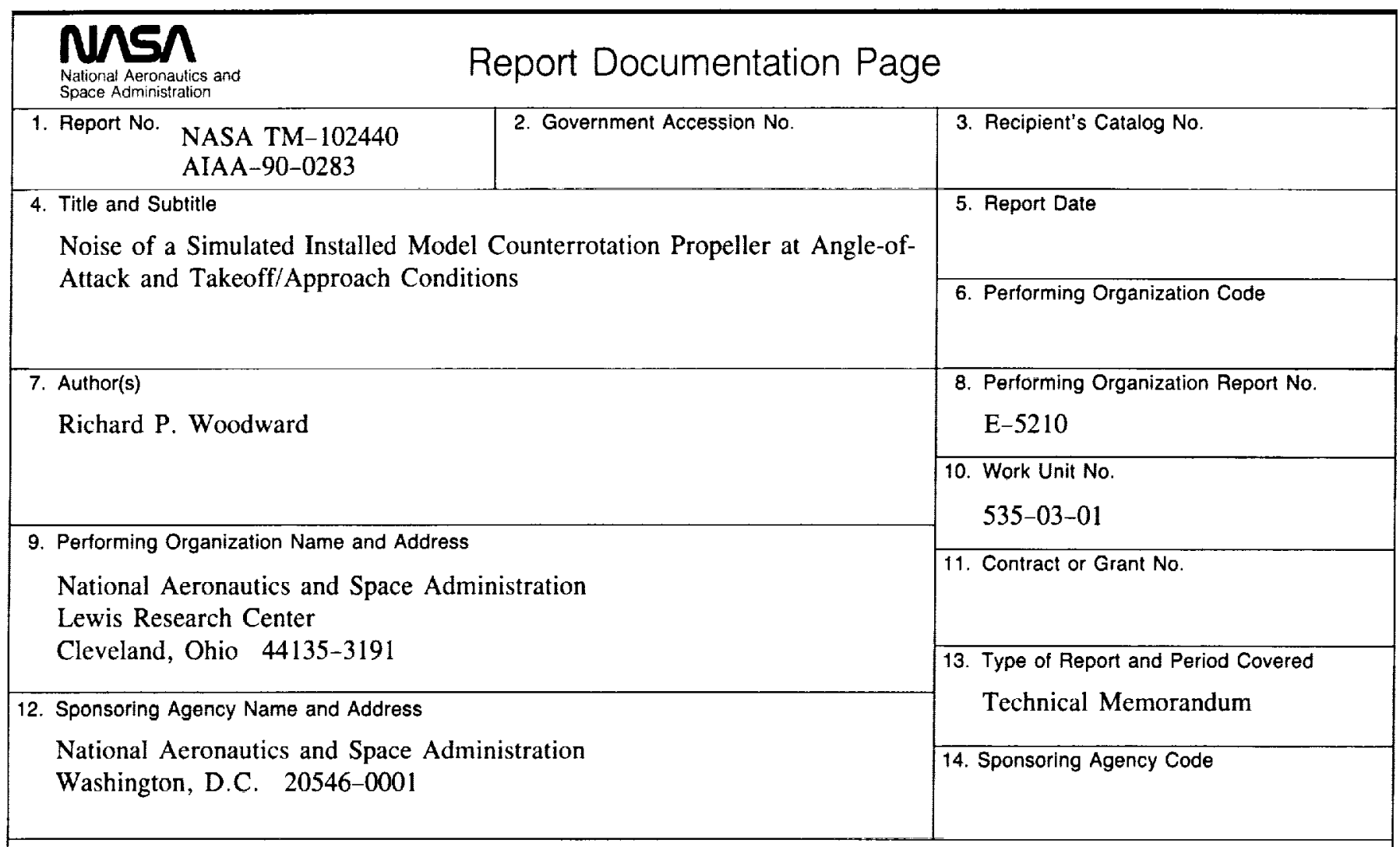

15. Supplementary Notes

Prepared for the 28th Aerospace Sciences Meeting sponsored by the American Institute of Aeronautics and Astronautics, Reno, Nevada, January 8-11, 1990.

\section{Abstract}

Two modern high-speed advanced counterrotation propeller, F7/A7 and F7/A3 were tested in the NASA Lewis Research Center's 9-by 15-Foot Anechoic Wind Tunnel at simulated takeoff/approach conditions of 0.2 Mach. Both rotors were of similar diameter on the F7/A7 propeller, while the aft diameter of the F7/A3 propeller was 85 percent of the forward propeller to reduce tip vortex-aft rotor interaction. The two propellers were designed for similar performance. The propellers were tested in both the baseline configuration and "installed" configuration consisting of a simulated upstream nacelle support pylon and fuselage section. Acoustic measurements were made with a "polar" microphone probe which recorded sideline directivities at various azimuthal locations. Aerodynamic measurements were also made to establish propeller operating conditions. The propellers were run at initial blade seting angles for the baseline and installed configurations, and also with the blade setting angles adjusted to achieve equal forward/aft torque ratios at angle of attack with the pylon and fuselage simulation in place. Data are presented fo propeller operation at 80 and 90 percent of design speed. (The forward rotor design tip speed was $238 \mathrm{~m} / \mathrm{sec}(780 \mathrm{ft} / \mathrm{set})$ ). Both propellers were tested at the maximum rotor-rotor spacing of $14.99 \mathrm{~cm}(5.90 \mathrm{in}$.) based on the pitch change axis separation. Data presented in this report are for $0^{\circ}$ and $\pm 8^{\circ}$ propeller axis angle of attack. Results are presented for the baseline, pylon-alone, and pylon and fuselage configurations. The forward and aft rotor power coefficients and fundamental rotor-alone tone levels were directly controlled by propeller axis angle of attack. The second-order rotor-alone tones were strongly influenced by the upstream pylon wake at 80 percent speed; however, rotor-alone mechanisms controlled the tone levels at 90 percent speed. Rotor-rotor interaction tones were essentially unaffected by the presence of the simulated installation.

17. Key Words (Suggested by Author(s))
Counterrotation
Turboprop
Noise
18. Distribution Statement Unclassified - Unlimited Subject Category 71 